\title{
Estimation of Seismic Site Coefficient and Seismic Microzonation of Imphal City, India, Using the Probabilistic Approach
}

\author{
Kumar PALLAV ${ }^{1}$, S.T.G. RAGHUKANTH ${ }^{2}$, \\ and Konjengbam D. SINGH ${ }^{3}$
}

${ }^{1}$ Department of Civil Engineering, Motilal Nehru National Institute of Technology

Allahabad, India; e-mail: kumarpallav23@gmail.com

${ }^{2}$ Department of Civil Engineering, Indian Institute of Technology Madras, India;

e-mail: raghukanth@iitm.ac.in

${ }^{3}$ Department of Civil Engineering, Indian Institute of Technology Guwahati, India; e-mail: darun@iitg.ac.in

\begin{abstract}
Seismic site coefficients $\left(F_{s}\right)$ for Imphal city have been estimated based on 700 synthetically generated earthquake time histories through stochastic finite fault method, considering various combinations of magnitudes and fault distances that may affect Imphal city. Seismic hazard curves and Uniform Hazard Response Spectra (UHRS) are presented for Imphal city. $F_{s}$ have been estimated based on site response analyses through SHAKE-91 for a period range of engineering interest (PGA to $3.0 \mathrm{~s}$ ), for $5 \%$ damping. $F_{s}$ were multiplied by UHRS values to obtain surface level spectral acceleration with 2 and $10 \%$ probability of exceedance in 50 year ( $\sim 2500$ and $\sim 500$ year) return period. Comparison between predicted mean surface level response spectra and IS-1893 code shows that spectral acceleration value is higher for longer periods (i.e., $>1.0 \mathrm{~s}$ ), for $\sim 500$ year return period, and lower for periods shorter than $0.2 \mathrm{~s}$ for $\sim 2500$ year return period.
\end{abstract}

Key words: seismic site coefficient, seismic microzonation, ground motion. 


\section{INTRODUCTION}

Past earthquakes have demonstrated that the local soil plays significant role in the characteristics of ground motions. Building codes have incorporated soil amplification effects by specifying few site categories (soil profile types) and assigning soil/site amplification effects for each site category. According to Martin and Dobry (1994) the site coefficients $F_{a}$ specified in the National Hazard Reduction Program (NEHRP) provisions (BSSC 1995) are about the mean values and the site coefficients $F_{v}$ are approximately the mean plus one standard deviation values. However, the variations in these site coefficients are not specified. The work carried out by Hwang et al., (1997) specified the site coefficient for site categories given in the 1994 NEHRP provisions (BSSC 1995) using the ground motions expected to occur in the eastern United States. A set of generic site coefficients was derived and summarized similar to NEHRP site coefficients (BSSC 1995), with an added dimension of the Mississippi Embayment deposits thickness to the Paleozoic rock by Park and Hashash (2005). All these site coefficients categorize only the type of soil and do not correlate it with rock-level time histories. In this paper, a simple procedure has been established to compute the seismic site coefficients $\left(F_{s}\right)$ due to seismic loading (earthquake timehistory) that may be useful for design engineers to obtain the surface level response. The study has been performed for Imphal city (capital of Manipur State, India; Fig. 1) and $F_{s}$ with respect to 700 synthetically generated earthquake time-histories have been obtained. These time-histories have been
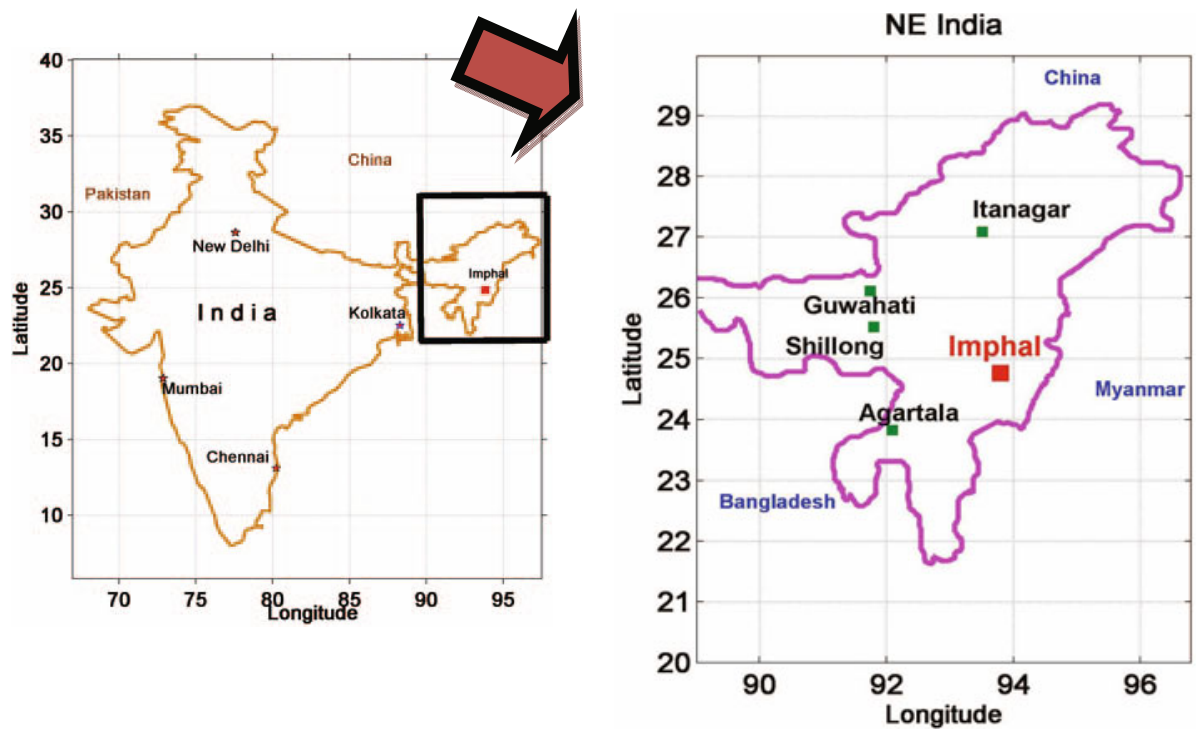

Fig. 1. Location of Imphal city. 
generated at a regular interval of magnitude of 0.5 and distance of $20 \mathrm{~km}$, for $M_{w}$ magnitudes between 5.0 and 8.5 , and $5-200 \mathrm{~km}$ distance using finite-fault seismological model (Motazedian and Atkinson 2005) in conjunction with equivalent linear site response analyses (Idriss and Sun 1992) on all 122 borehole locations of Imphal city. Further, $F_{s}$ are used to get the surface level response for input rock level motion. Pallav et al. (2012) have already performed the probabilistic seismic hazard analysis of Manipur State in which the rock level PGA for Imphal city has been estimated for 2 and $10 \%$ probability of exceedence in 50 year ( 2500 and $\sim 500$ year) return period. Surface level response for Imphal city has been estimated by multiplying the rock level input with $F_{s}$. Further on, seismic microzonation maps at PGA, 0.3 and $1.0 \mathrm{~s}$ with $\sim 500$ and $\sim 2500$ year return period have been prepared for Imphal city and a comparison was made between predicted mean surface level response spectra and the existing Indian Code of Practice (IS-1893 2002).

\section{ABOUT IMPHAL CITY}

Imphal city $\left(24^{\circ} 48^{\prime} \mathrm{N}, 93^{\circ} 56^{\prime} \mathrm{E}\right)$, the capital of Manipur state, is one of the oldest cities of North East India; it forms the central part of the oval-shape Imphal valley. The developmental growth of city has been very slow for various political and geographical reasons compared to other capital cities of India. However, in the recent years, an increase in population/population density in and around Imphal city has been observed. According to the 2011 census, Imphal city has a population of 264986 ; which is around $10 \%$ of the entire state's population. The growth pattern has been considerably influenced by physiographic characteristic of Imphal city. Major growth has taken place in the central area - near Kangla Palace, and towards the south along the highways (NH-39 and NH-150), which is shown in Fig. 2.

In recent time, local government has taken up several important infrastructural building programmes to accommodate increase in population. New buildings, viz., capital buildings, high court, city convention center, etc., are coming up along with some new international projects, like rail link from Manipur to Vietnam, trilateral highways project between India, Myanmar, and Thailand, digital connectivity of optical fiber cable link between Moreh in Manipur and Mandalay in Mayanmar (PTI 2010) are in pipeline. As such, due to proximity Indo Burma Range (IBR), Shillong Plateau (SP), and Naga Disang Thrust, vulnerability of Imphal city to damaging earthquakes has increased. In view of this, it is pertinent to understand the near surface soil effect on Imphal city due to earthquake events and model the local site that helps engineers and designers to use the developed parameters, i.e., seismic site coefficients, due to seismic loading in their design. 


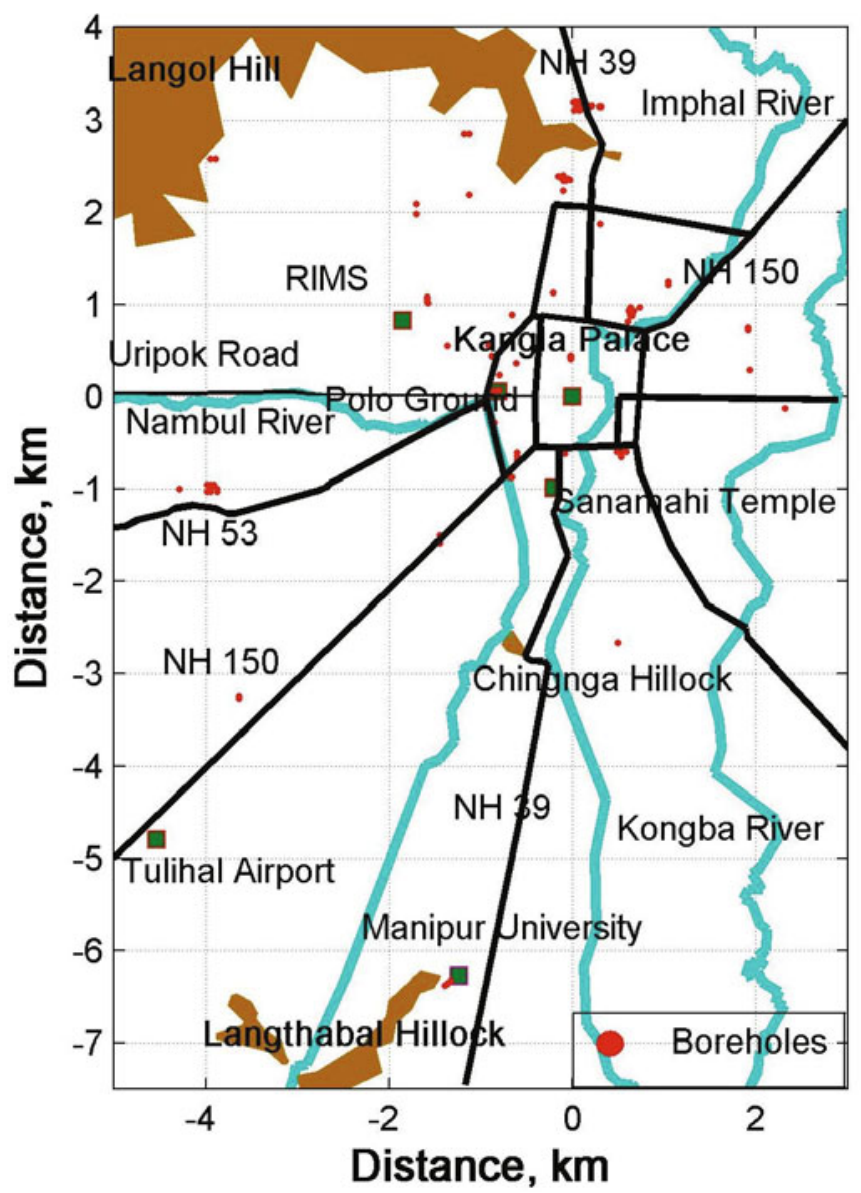

Fig. 2. Imphal city with important places, rivers, and transportation network along with boreholes location (origin $(0 \mathrm{~km}, 0 \mathrm{~km})$ corresponds to latitude of $24.81^{\circ}$ and longitude of $93.94^{\circ}$, at Kangla palace).

\section{SEISMIC SETUP AROUND IMPHAL CITY}

In a period of 147 years (1866-2013), North East (NE) India has experienced more than 2200 earthquakes of magnitude $M_{w} \geq 4.0$. These earthquakes, of both crustal as well as subduction zone origin, are close to Imphal $(<300 \mathrm{~km})$. Seismotectonic features in a broad region around Imphal city have been identified and described basing on the seismotectonic atlas of India (GSI 2000). Figure 3 (after Pallav et al. 2010, 2012) shows that almost the entire region around Imphal city is surrounded by faults. These faults contribute to tectonic activity in the region, which is mainly due to the interaction between the north-south convergence along the Himalayan boundary, 


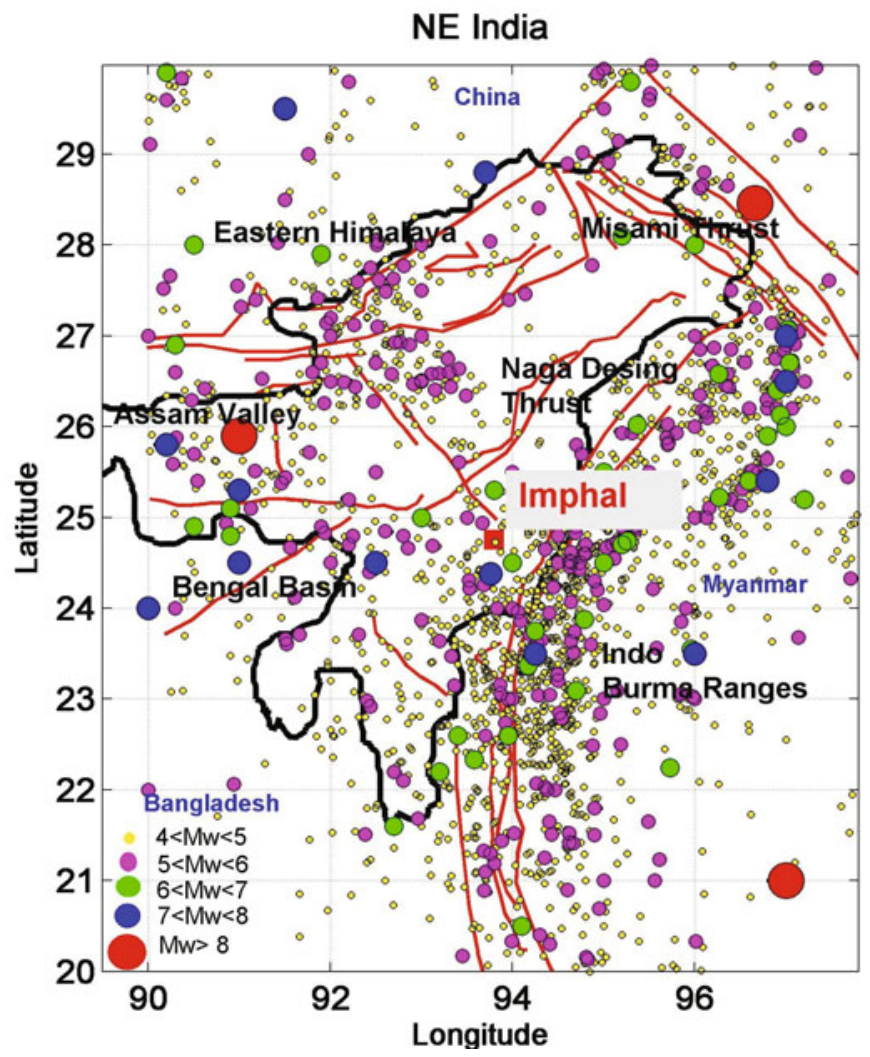

Fig. 3. Seismotectonic setup around Imphal city with seven seismic blocks along with epicenters (1866-2013).

and east-west convergence along the IBR. Based on its seismotectonic features and geology, NE India is broadly divided into seven seismic zones. These are: 1 - Indo-Burma Ranges, IBR; 2 - Eastern Himalaya, EH; 3 Mishmi Thrust, MT; 4 - Shillong Plateau, SP; 5 - Naga-Disang thrust, ND; 6 - Bengal basin, BB; and 7 - Assam Valley, AV (Goswami and Sarmah 1982, Nandy 2001). The details on seismicity of NE India and damages incurred due to past earthquake in Imphal city/Manipur state were discussed in Raghukanth et al. (2009), and Kumar et al. (2010, 2012).

\section{GEOGRAPHY, GEOLOGY AND LOCAL SOIL CONDITION}

\subsection{Geography}

Imphal valley (also known as Manipur valley) is surrounded by a series of mountain chains, i.e., Patkai hills on the north and north-east and the Manipur hills, Lushai hills, Naga hills, and Chin hills on the south, running from 
north to south, forming an integral part of IBR (Laiba 1992, Ibotombi 2000). It has NNW-SSE orientation with a gentle tilting slope towards the south, at $798 \mathrm{~m}$ above mean sea level (a.m.s.l.) at the extreme north, and $746 \mathrm{~m}$ a.m.s.l. at the south. The structural and tectonic pattern near Imphal valley is transitional between the NE-SW trending pattern of Naga-Patkai hills and the N-S trend of Mizoram and Chin hills (Brunnschweiler 1974). These hills comprise geologically young rock formations due to Tertiary upward displacement of the Himalayas from the shallow bed of the Tethys Sea. The rocks are mainly of Tertiary and Cretaceous sediments with minor igneous and metamorphic rocks. Geomorphologically, the valley area can be categorized into five major units: 1 - moderate to high structural cum Denudational hills, which can be seen as the hills and mountains surrounding the valley, 2 - residual hills composed of hillocks and hills which are scattered in the valley (e.g., Langol and Chingna hills), 3 - piedmont plain features along the foothills, 4 - older alluvial plains of alluvium deposits near foothills of Imphal valley, and 5 - younger alluvial plains having lower elevation than the older alluvial plains and which are mostly flat (Singh 2004). Imphal valley is surrounded by four major river basins, viz., the Barak river basin (Barak valley) to the west, the Manipur river basin in central Manipur, the Yu river ba$\sin$ in the east, and a portion of the Laniye river basin in the north (Haokip 2007). The river basins have the major rivers: Imphal, Iril, Nambul, Sekmai, Chakpi, Thoubal, and Khuga. All these rivers originate from the surrounding hills and deposit their sediment load in the Loktak lake (Laiba 1992) located in Imphal valley.

\subsection{Geology}

Geological information and a detailed geological report on Imphal city are still not available. As per the report published by Manipur Science and Technology Council (MASTEC 2007), Imphal valley is almost flat in nature, filled with fluvio-lacustrine dark grey to black clay, silt, and sand alluviums deposits. The major portion of sediments are clay and mixture of clay and sand, whilst silt and sand forms lensoids and bands within clay. As per the authors' knowledge, the bed rock profile has not been mapped; however, the MASTEC (2007) report suggests that the average thickness of alluvium is at least $\sim 100-150 \mathrm{~m}$. It is suggested that the basement mainlyconsists of Disang sediments. The extension of the basement faults led to the growth of isolated hillocks, as remnants of horsts. This forms the basis of tectonic beginning and creation of Imphal valley (Ibotombi 2000). However, this is in disparity to the erosional formation of valley, according to which the valley was formed due to filling of river borne sediments in the Loktak lake, the original lake that engulfed the entire valley once. Laiba (1992) as another theory 
suggesting the fluvio-lacustrine origin of the valley due subsequent earthquakes in the area.

\subsection{Local soil condition}

Imphal is a city located on the banks of Imphal, Nambul, and Kongba rivers that have left several palaeoseismic channels over which the present human settlement exists. The main constituents of Imphal valley are sands, clays, silts, etc. of fluvio-lacustrine origin, whereas ferruginous red soils are found near isolated foothill regions. Alluvial soils occur near the riverbanks. Clayey soils in the valley region are rich in humus. In the low-lying areas of Imphal city, i.e., Lamphelpat, Takyelpat, Prompat, Kakwapat ("pat" means lake), virgin soils as clayey loam, dark clayey, and boggy kind of soils are found (Laiba 1992).

The near surface soil conditions play an important role in soil amplification potential of a site. It is therefore essential to take into account the soil properties of the near surface soil layers to obtain the surface level ground motion. The shear wave velocity profiles and Cone Penetration Test (CPT) data are not readily available for sites in Imphal city. However, Standard Penetration Test (SPT-N) data and soil characteristics are available for several sites, 122 location, of Imphal city. These sites are scattered over an area of about $11.5 \times 8 \mathrm{~km}$ along the NH-39 and NH-53, as shown in Fig. 2. The SPT-N values have been measured at $1.5 \mathrm{~m}$ interval along the depth of boreholes. The boreholes depth ranges from 6 to $20 \mathrm{~m}$ for most of the sites. However, for important construction projects, SPT-N has been carried out down to a depth of $30 \mathrm{~m}$. The type of soil deposits in Imphal city comprises of sandy clay, silty clay, and clayey along with organic matters deposited in different layers. They are loose in density due to typical alluvial/fluvial deposits. The SPT-N data shows that even at a depth of $25-30 \mathrm{~m}$ below the ground surface the values are low, of the order of 12 to 20 , except of few places where they are about 30-40. In addition to the sides of NH-39, $\mathrm{NH}-53$, and NH-150 roads, most of these boreholes are located around the Kangla Palace area that houses several commercial and administrative establishments. Further, the classification of the site categories present in Imphal city has been made based on International Building Code (IBC-2006 2006), in which the average standard penetration resistance $(\bar{N})$ at all the boreholes is computed by the following equation:

$$
\bar{N}=\frac{\sum_{i=1}^{n} d_{i}}{\sum_{i=1}^{n}\left(d_{i} / N_{i}\right)},
$$



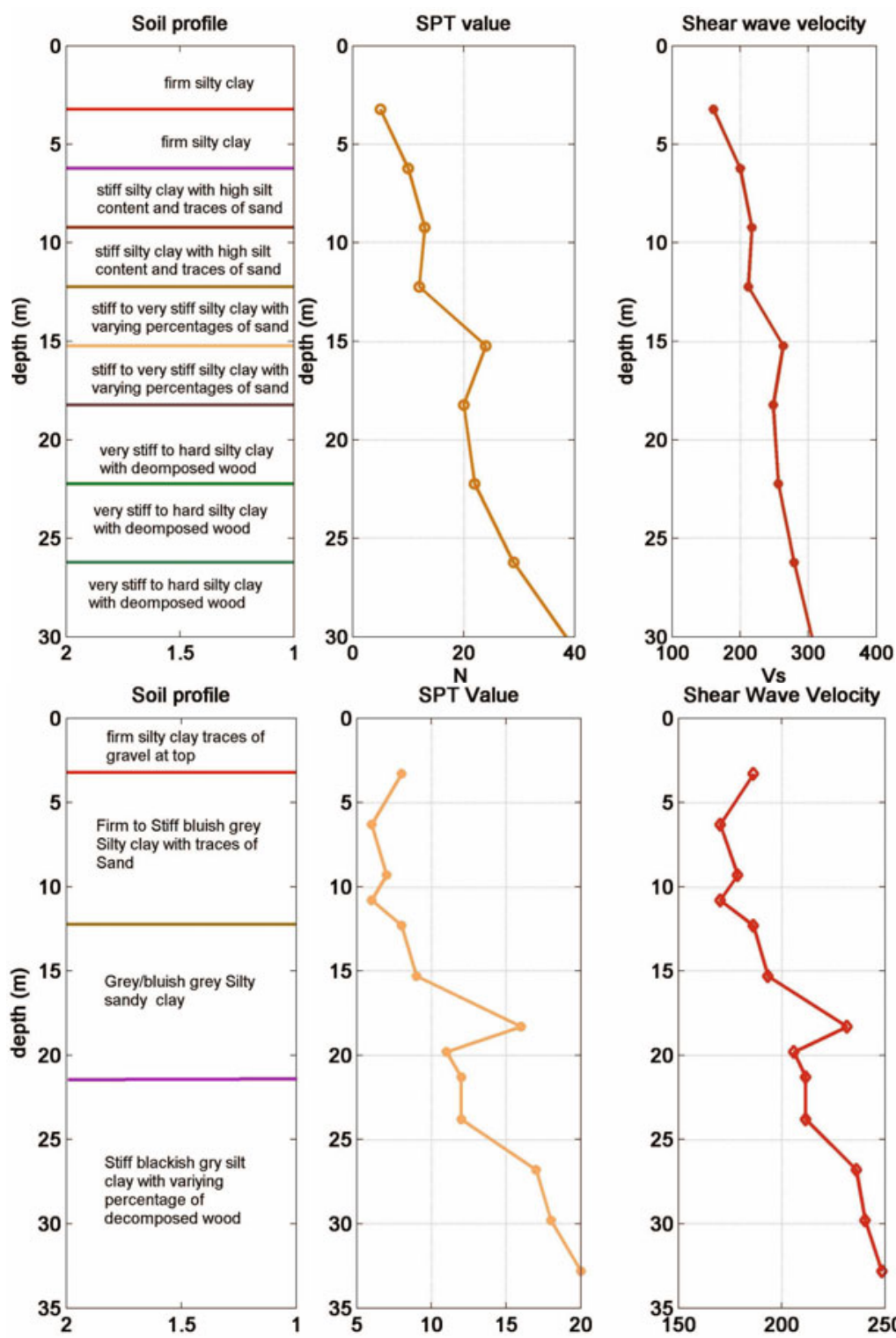

(a)

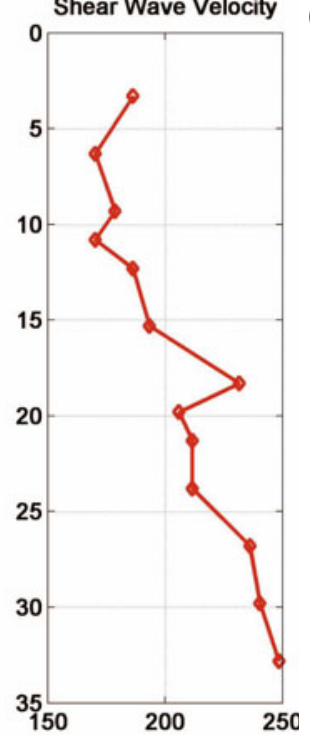

Fig. 4. Typical D (a) and E (b) type soil profile, SPT-N value, and shear (b) velocity.

where $d_{i}$ and $N_{i}$ are the thickness and SPT-N value of each layer, respectively, and $n$ is the total number of soil layers. Out of the 122 boreholes in Imphal city which are considered in the present analysis, 114 boreholes are classified as soil class E-type $(\bar{N}<15)$ while remaining 8 boreholes are of 
soil class D-type $(15<\bar{N}<50)$ following the classification concept applied by IBC-2006. A typical D-type and E-type subsurface soil condition and SPT-N value profile are shown in Fig. 4. It may be noted that IBC-2006 requires soil data down to a $30 \mathrm{~m}$ depth. In present study, as not all the soil data down to $30 \mathrm{~m}$ depth are available for site classification, the mean SPT-N value was estimated from those boreholes for which SPT values were available down to $30 \mathrm{~m}$ depth, and it has been used as additional data for the remaining depth down to $30 \mathrm{~m}$.

\section{DETERMINATION OF ROCK LEVEL ACCELERATION TIME HISTORIES}

Due to the unavailability of strong motion records of past earthquakes that caused damages to Imphal city, the synthetic ground motion is simulated by stochastic finite fault model. In this model, features of source and path are modelled as primary system parameters and the effect of near surface soil layers is treated as a secondary modification. The rock level ground motions are simulated by stochastic finite fault approach of Motazedian and Atkinson (2005) which is based on the concept of dynamic corner frequency and pulsing subfaults.

In the present approach, the fault is divided into $N$ subfaults and they are represented as point sources. The triggering occurs when the rupture front spreads radially from the nucleation point and it reaches their center. The sub-fault acceleration time histories are propagated to the observation point by considering specified distance-duration curves and attenuation model. The Fourier amplitude spectrum of ground motion $[Y(r, f)]$ due to the $j$-th subfault at a site is derived from the point source seismological model, expressed as

$$
Y_{j}(r, f)=\left(\frac{\mathrm{M}_{0} D_{j}}{\sum_{j=1}^{N} D_{j}}\right)\left(\frac{N(2 \pi f)^{2} \sum_{f}\left(\frac{f^{2}}{1+\left(f / f_{0}\right)^{2}}\right)^{2}}{\left(1+\left(f / f_{0 j}(t)\right)^{2}\right) \sum_{f}\left(\frac{f^{2}}{1+\left(f / f_{0 j}(t)\right)^{2}}\right)^{2}}\right)^{1 / 2}\left(\frac{\sqrt{2}<\mathrm{R}_{\theta \phi}>}{4 \pi \rho \mathrm{V}_{\mathrm{s}}^{3}}\right)\left(G e^{-\frac{\pi f f_{j}}{\mathrm{~V}_{\mathrm{s}} Q}}\right)\left(F(f) e^{-\pi f \kappa_{0}}\right),
$$

where $M_{0}$ is the total seismic moment of all the subfaults, $G$ refers to the geometric attenuation, $r_{j}$ is the subfault distance from the site, $V_{s}$ is the shear wave velocity, and $Q$ is the quality factor of the region. $D_{j}$ is the average final slip acting on the $j$-th subfault, $f_{0 j}(t)$ is the dynamic corner frequency (Motazedian and Atkinson 2005), and $F(f)$ represents site amplification due to propagation of earthquake waves from the source region toward the surface. The term $\exp \left(-\pi f \kappa_{0}\right)$ is a high cut filter which takes care of the rapid 
spectral decay at high frequencies (Anderson and Hough 1984). $\left\langle R_{\theta \phi}\right\rangle$ is the radiation coefficient averaged over an appropriate range of azimuths and take-off angles and $\rho$ is the density of the crust at the focal depth. The dynamic corner frequency $f_{0 j}(t)$, the seismic moment and the stress drop $(\Delta \sigma)$ are related through the following equation

$$
f_{0 j}(t)=4.9 \times 10^{6}\left(N_{R}(t)\right)^{-1 / 3} N^{1 / 3} V_{s}\left(\frac{\Delta \sigma}{M_{0}}\right)^{1 / 3},
$$

where $N_{R}(t)$ is the cumulative number of ruptured subfaults at time $t$. The corner frequency at the end of the rupture, $f_{0}$, is obtained by substituting $N_{R}(t)=N$ in Eq. 3. Motazedian and Atkinson (2005) introduced the concept of pulsing area where the cumulative number of active subfaults, $N_{R}(t)$, increases with time at the initiation of rupture, to attain a constant magnitude at some fixed percentage of the total rupture area referred to as percentage pulsing area; this accounts for realistic model of earthquake rupture. This parameter (i.e., pulsing area) determines the number of active subfaults during the rupture of $j$-th subfault. These numerous subfaults are used in Eq. 3 for computing the dynamic corner frequency. Finite fault seismological model for North East India has been calibrated by Raghukanth and Somala (2009). The range of stress drop, pulsing percentage and the quality factor for IndoBurma, Shillong Plateau, and Bengal basin tectonic blocks have been derived from the strong motion data of minor and moderate events in NE India. Pallav et al. (2012) has studied that Indo Burmes Range and Shillong Plateau are situated closer to Imphal and contribute significantly in seismic hazard. Hence the parameters used to study in the present work are shown in Table 1 . The quality factor, $Q(f)$, geometric spreading, and distance-dependent

Table 1

Input parameters in the stochastic finite fault seismological model

(Raghukant and Somala 2009)

\begin{tabular}{|l|c|c|}
\hline \multicolumn{1}{|c|}{ Parameter } & Shillong Plateau & Indo-Burma Ranges \\
\hline Depth to top of the fault $[\mathrm{km}]$ & 5 & 60 \\
Stress drop [bars] & $50-100$ & $50-100$ \\
$Q(f)$ & $221 \mathrm{f}^{0.89}$ & $431 \mathrm{f}^{0.73}$ \\
Site effects $[F(f)]$ & Quarter wavelength & Quarter wavelength \\
Kappa factor & 0.03 & 0.03 \\
Pulsing percentage & $25-60$ & $25-60$ \\
Rupture velocity & $0.8 \beta$ & $0.8 \beta$ \\
Slip distribution & Random field & Random field \\
\hline
\end{tabular}


duration operators for North East India are taken from Raghukanth and Somala (2009).

Acceleration time histories of length equal to the strong motion duration (Boore and Atkinson 1987) are simulated for each subfault from the point source seismological model of Boore (1983). The simulated acceleration time histories for all the subfaults are summed up with a time delay $\Delta t_{j}$ to obtain the ground motion acceleration, $a(t)$, from the entire fault as

$$
a(t)=\sum_{j=1}^{N} a_{j}\left(t+\Delta t_{j}\right) .
$$

The ground motion samples obtained are based on a given set of model parameters, which are themselves uncertain. Thus the sample ground motions from a suite of such simulations may still not reflect all the variability observed in real ground motion. To account for this, the slip distribution, stress drop and pulsing percentage are treated as random variables, distributed uniformly about a mean value.

These methods are successfully validated for Imphal city (Raghukanth et al. 2009, and Pallav et al. 2010). Altogether 700-earthquake time-history has been generated for different combinations of magnitudes $\left(M_{w}\right.$ of 5-8.5) and distances $(20-200 \mathrm{~km})$ from the faults under consideration and their mean Peak Ground Acceleration (PGA) distribution is shown in Fig. 5. The mean PGA is relatively low at lower magnitude $\left(M_{w}<6\right)$ or large distance (greater than $90 \mathrm{~km}$ ).

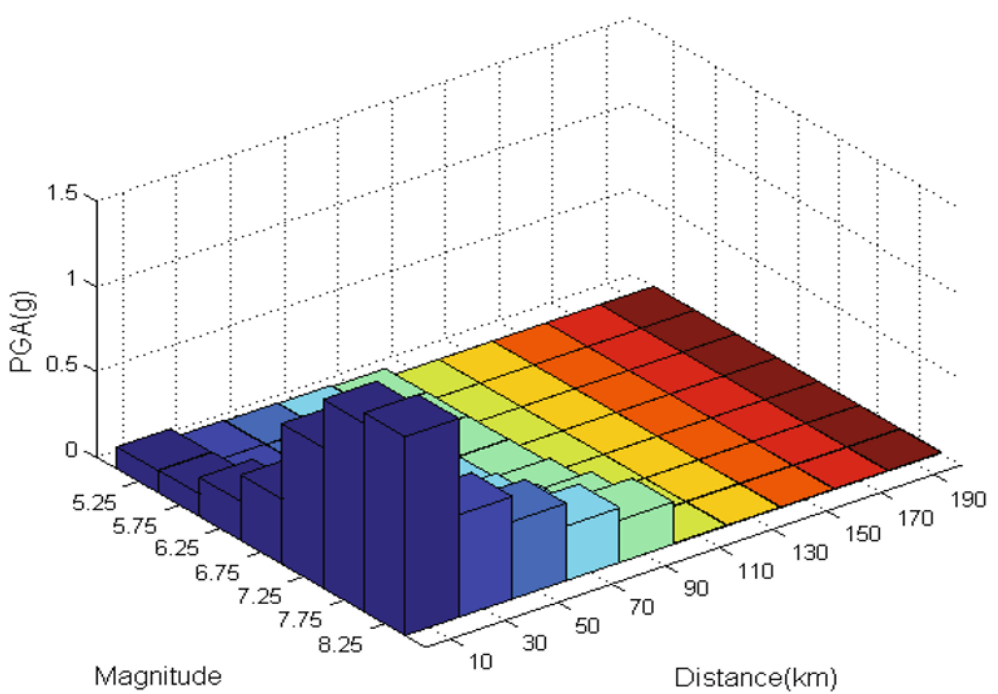

Fig. 5. Mean PGA distribution. 


\section{SOIL AMPLIFICATION}

As $V_{s}$ (shear-wave velocity) values were not mapped for Imphal city, they have been computed from the $N$ values using the empirical relation $V_{s}=97 N^{0.314}$ of Imai and Tonouchi (1982), where $N$ is SPT $N$ value and $V_{s}$ is in $\mathrm{m} / \mathrm{s}$. Although there are many equations available for computing $V_{s}$, intention to choose the above equation is its applicability to all types of soil and, moreover, the fact that methods of conducting SPT in Indian and Japanese standards are quite similar. Further, it is assumed that the top soil layer (i.e., alluvial/fluvial deposits) is underlain by rock. Modification of acceleration time history between soft rock and soil site is a non-linear problem in one dimension and hence, for such sites, amplification was already found by the nonlinear site response analysis in Raghukanth et al. (2009). The nonlinear behavior of the soil, i.e., reduction of shear modulus and increase of damping ratio with increasing/decreasing shear strain are accounted by using equivalent linear soil properties. For this purpose, shear modulus versus shear strain curves and damping ratio versus shear strain curves proposed by Vucetic and Dobry (1991) for different types of soil, i.e., clay and sand (Fig. 6a and b) whereas for rock, the curve proposed by Schnabel et al. (1972) has been used in the present analysis (Fig. 6c), in which $G$ and damping ratio is approximated by adopting equivalent linear values. The equivalent linear value of $G$ is the secant modulus of a first hysteresis loop. Similarly, the equivalent linear value of damping is the energy loss in the first hysteresis loop. The equivalent linear approach considers the variation of $G$ and damping ratio for different strain values. Equivalent nonlinear site response analysis has been carried out using the software SHAKE-91 of Idriss and Sun (1992). The simulated acceleration time history at rock level from finite fault seismological model for Imphal city has been used as input in SHAKE-91 to generate surface level time histories, in which the vertical propagation of SH waves may be represented by a stack of infinitesimal elements. One-dimensional equation of motion for vertically propagating $\mathrm{SH}$ waves can be written as follows:

$$
\rho \frac{\partial^{2} u}{\partial t^{2}}=\frac{\partial \sigma_{x z}}{\partial z} .
$$

The stress-strain relationship for such a model is given as

$$
\tau=G \gamma+\eta \frac{\partial \gamma}{\partial t} .
$$

Substituting Eq. 5 into Eq. 6 with $\tau=\sigma_{x z}$ and $\gamma=\partial u / \partial z$, we get

$$
\rho \frac{\partial^{2} u}{\partial t^{2}}=G \frac{\partial^{2} u}{\partial z^{2}}+\eta \frac{\partial^{3} u}{\partial z^{2} \partial t} .
$$




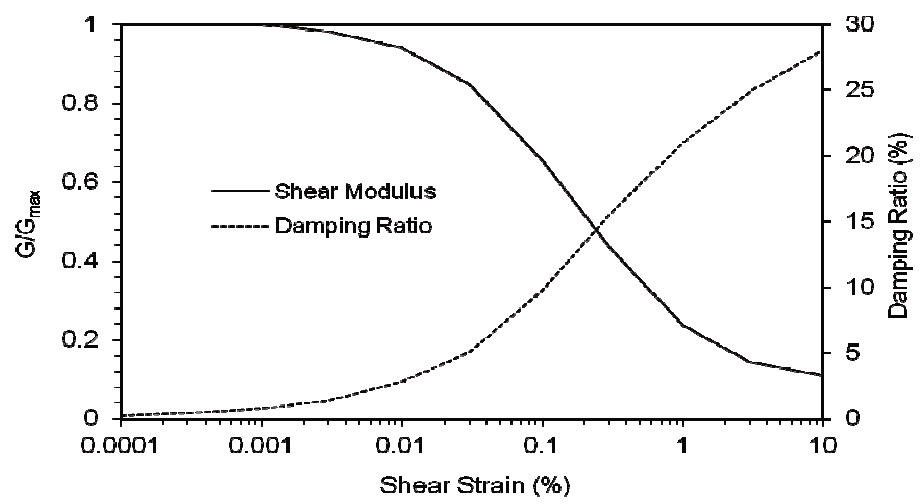

(a)

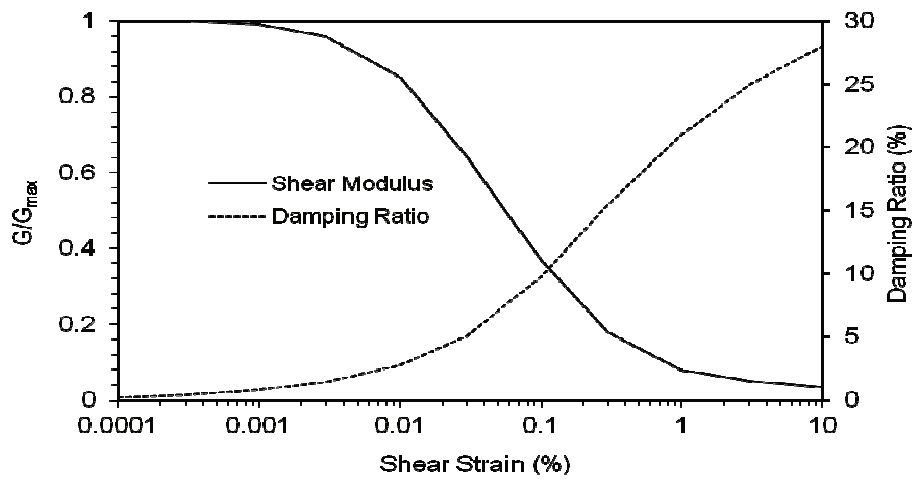

(b)

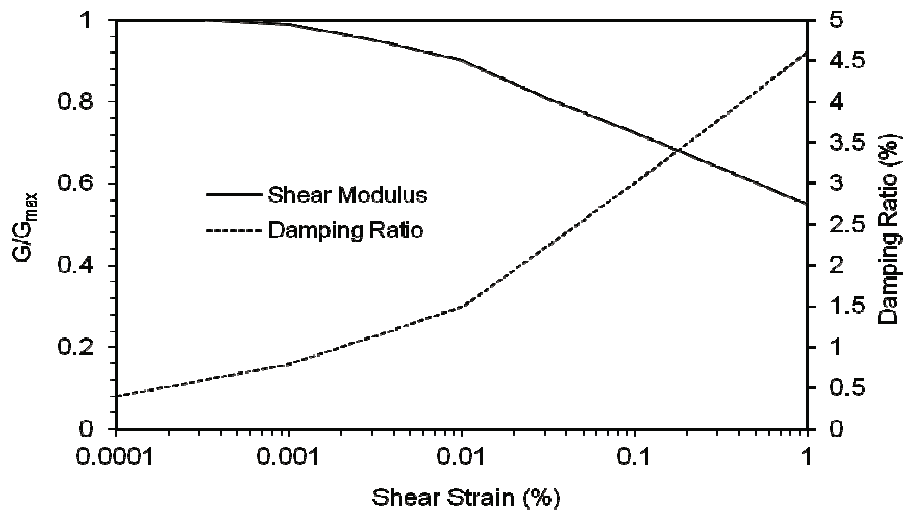

(c)

Fig. 6. Modulus reduction curve and damping curves: (a) clay, (b) sand (Vucetic and Dobry 1991), and (c) rock (Schnabel et al. 1972).

The solution to the wave equation (Eq. 7) for a harmonic motion of frequency $\omega$ is given by:

$$
u(z, t)=E e^{i(k z+\omega t)}+F e^{-i(k z-\omega t)},
$$




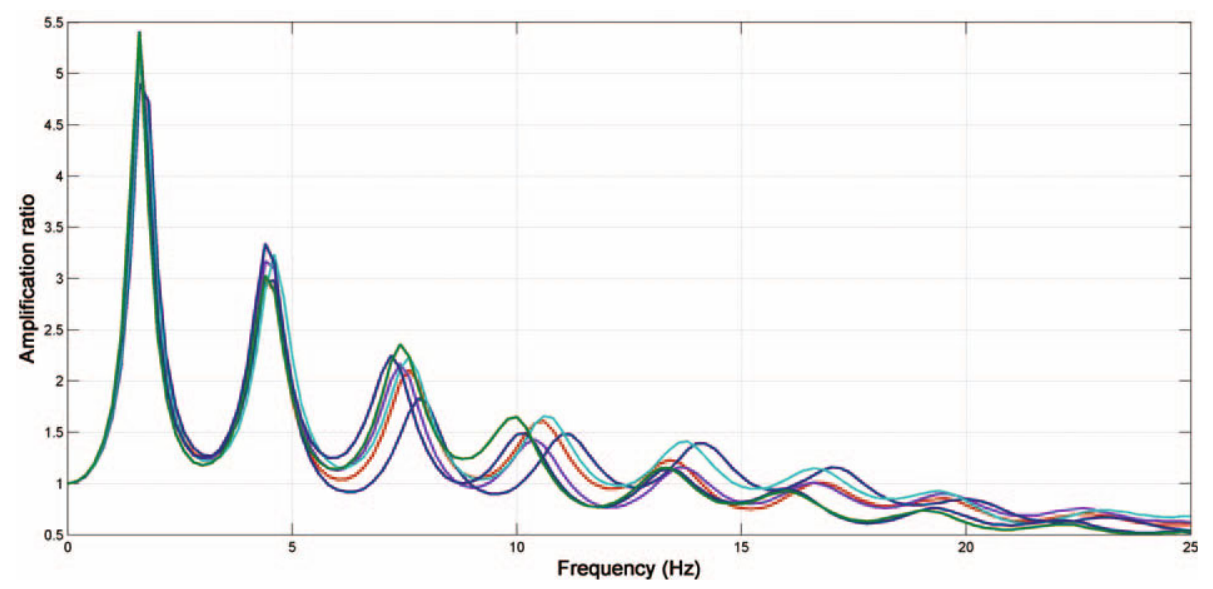

Fig. 7. Frequency response functions of sample of six soil profiles in Imphal city.

where the first term represents the incident wave travelling in the negative $z$ direction (upwards) and the second term represents the reflected wave travelling in the positive $z$ direction (downwards).

The frequency response functions (FRF) are defined as the ratio of acceleration at the ground surface, computed through SHAKE-91, to the acceleration at the bedrock level; for 6 sites the soil profiles are shown in Fig. 7. It can be seen that the maximum amplitude occurred in the range of $1-3 \mathrm{~Hz}$, which corresponds to the range of the first natural frequency of the soil deposits, respectively, and the same is observed for almost all the sites present in the Imphal city.

\section{SITE COEFFICIENT DETERMINATION}

The above analysis gives an idea about the amplification of ground motion in Imphal city. To make it simpler for estimating the site response in Imphal city for application purpose, the soil sites in Imphal are modeled in terms of seismic site coefficients defined as the ratio of surface level response to rock level response at different periods, as shown below.

$$
F_{s}=\frac{\text { surface level response }}{\text { rock level response }}=\frac{S_{r}}{r_{b r}} .
$$

For each site, site response analysis has been performed using Idriss and Sun (1992) procedure for all the 700 time histories and correspondingly 700 $F_{s}$ values were estimated for one site for all periods of engineering interest (PGA to $3.0 \mathrm{~s}$ ). Then, making use of statistical regression, single site coefficient for all periods has been estimated for the site. Similar procedure has 
been chosen for all other sites, with soil category of type $\mathrm{D}$ and $\mathrm{E}$ present in Imphal city.

In this study, the reference site is taken as B type rock site $(760 \mathrm{~m} / \mathrm{s}<$ $V_{s}<1500 \mathrm{~m} / \mathrm{s}$ ) found as hillock in Imphal (e.g., Chingmirong, Langol hill). The 700 response spectra were established for each of the two soil categories (D, E type) present in Imphal city, and the site coefficients at various selected periods were calculated. As the site coefficient $\left(F_{s}\right)$ is not a constant value (varies with rock level motion) for a particular site, regression analysis has been used to obtain an empirical relation of the form $\ln \left(F_{s}\right)=a_{1} r_{b r}+a_{2}+\delta$ between site coefficient $\left(F_{s}\right)$ and rock level motion $r_{b r}$, where $a_{1}$ and $a_{2}$ are regression coefficients and $\delta$ is the standard deviation. The distribution of $F_{s}$ corresponding to zero natural periods is plotted with respect to the corresponding bedrock, as shown in Figs. 8 and 9. Similarly, regression analysis has been performed for various natural periods (i.e., PGA of 0.04, 0.1, 0.2, $0.4,1,2$, and $3 \mathrm{~s}$ ) and the variations of $a_{1}, a_{2}$ and standard deviation are estimated at zero period, at PGA of 0.3 and $1.0 \mathrm{~s}$, respectively. For two typical

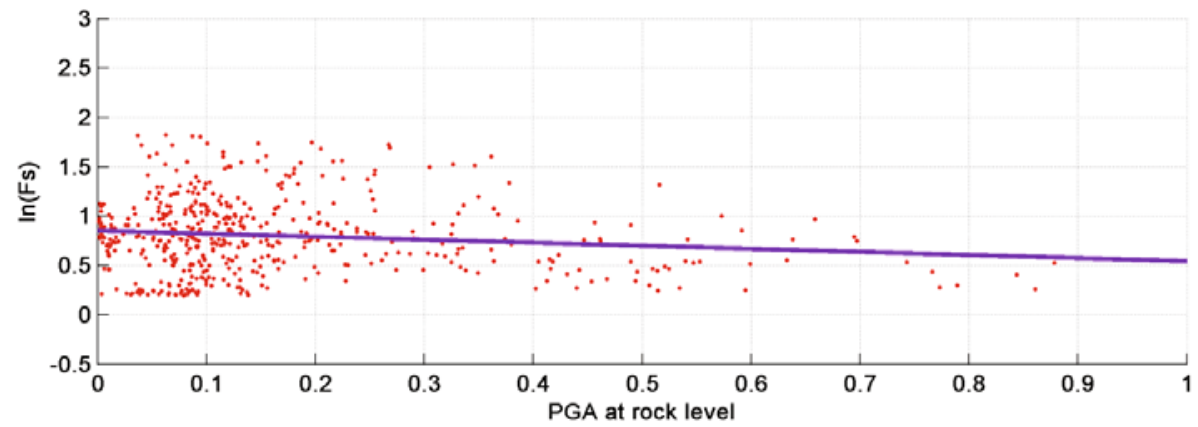

Fig. 8. Site coefficients for surface level ground motion corresponding to zero period for D type soil.

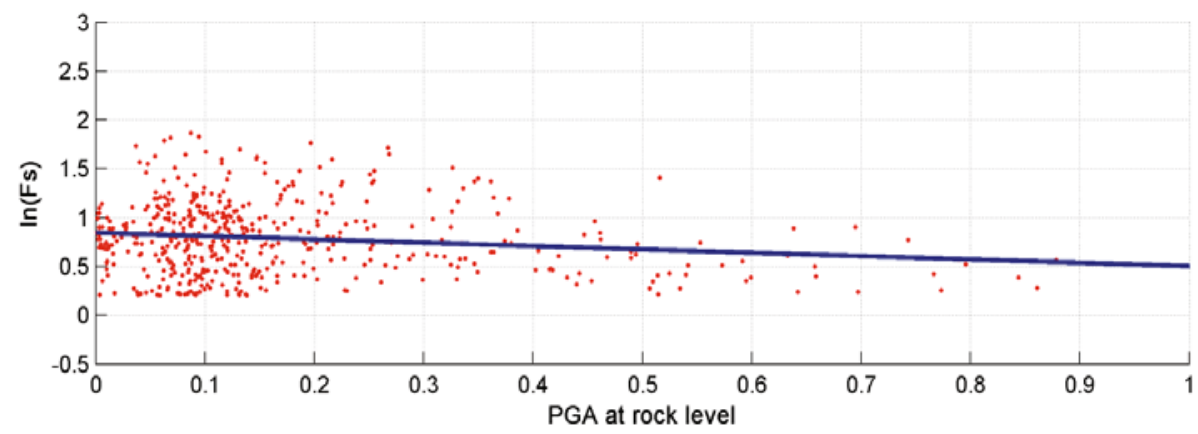

Fig. 9. Site coefficients for surface level ground motion corresponding to zero period for E type soil. 
types of sites present in Imphal city, viz., D and $\mathrm{E}$ types, the values of $a_{1}, a_{2}$, and $\delta$ are shown in Table 2 . These values can be used to compute the surface level response at different periods. Further Figs. 9a-c show the spatial variation of $a_{1}, a_{2}$, and standard deviation in Imphal city at PGA. Using $a_{1}, a_{2}$, and $\delta$ values, it is possible to obtain surface level spectral acceleration by using Eq. 10.

Table 2

Regression coefficients for typical D and E types

\begin{tabular}{|c|c|c|c|c|c|c|}
\hline \multirow{2}{*}{ Period } & \multicolumn{3}{|c|}{$F_{s}$ for D type site } & \multicolumn{3}{c|}{$F_{s}$ for E type site } \\
\cline { 2 - 7 } & $a_{1}$ & $a_{2}$ & $\delta$ & $a_{1}$ & $a_{2}$ & $\delta$ \\
\hline 0.0100 & -0.1940 & 0.4384 & 0.1464 & -0.5714 & 0.4851 & 0.1498 \\
0.0300 & -0.1398 & 0.4327 & 0.1484 & -0.5579 & 0.4863 & 0.1501 \\
0.0400 & -0.2025 & 0.4393 & 0.1464 & -0.5715 & 0.4852 & 0.1498 \\
0.1000 & -0.3108 & 0.4306 & 0.1307 & -0.8697 & 0.4581 & 0.1555 \\
0.2000 & -0.3276 & 0.5779 & 0.1342 & -0.5310 & 0.4622 & 0.1282 \\
0.3000 & -0.0428 & 0.3422 & 0.1239 & -0.4141 & 0.5727 & 0.1154 \\
0.4000 & -0.1490 & 0.4407 & 0.1243 & -0.3084 & 0.4232 & 0.1298 \\
1.0000 & 0.3080 & 0.3801 & 0.1143 & -0.0558 & 0.6763 & 0.1804 \\
2.0000 & 0.0607 & 0.1618 & 0.1180 & 0.3532 & 0.2332 & 0.1546 \\
3.0000 & -0.2362 & 0.1652 & 0.1347 & -0.0951 & 0.1950 & 0.1681 \\
\hline
\end{tabular}

Table 3

Average regression coefficients for $\mathrm{D}$ and $\mathrm{E}$ types soils

\begin{tabular}{|c|c|c|c|c|c|c|}
\hline \multirow{2}{*}{ Period } & \multicolumn{3}{|c|}{$F_{s}$ for D type } & \multicolumn{3}{c|}{$F_{s}$ for E type } \\
\cline { 2 - 7 } & $a_{1}$ & $a_{2}$ & $\delta$ & $a_{1}$ & $a_{2}$ & $\delta$ \\
\hline 0.0100 & -0.3065 & 0.5651 & 0.1913 & -0.6254 & 0.6784 & 0.2204 \\
0.0300 & -0.2830 & 0.5648 & 0.1933 & -0.6182 & 0.6800 & 0.2223 \\
0.0400 & -0.3075 & 0.5652 & 0.1913 & -0.6254 & 0.6784 & 0.2204 \\
0.1000 & -0.5640 & 0.5413 & 0.1767 & -0.7886 & 0.6379 & 0.2047 \\
0.2000 & -0.6609 & 0.6308 & 0.1677 & -0.7639 & 0.7343 & 0.2143 \\
0.3000 & -0.1006 & 0.5635 & 0.1735 & -0.3020 & 0.6205 & 0.2009 \\
0.4000 & -0.1627 & 0.6066 & 0.1598 & -0.4191 & 0.7035 & 0.2041 \\
1.0000 & -0.3406 & 0.4341 & 0.1569 & +0.0833 & 0.6157 & 0.2058 \\
2.0000 & -0.1430 & 0.1840 & 0.1478 & +0.0837 & 0.2437 & 0.2082 \\
3.0000 & -0.2193 & 0.1848 & 0.1652 & -0.3011 & 0.2249 & 0.1927 \\
\hline
\end{tabular}




$$
S_{r}=r_{b r} F_{s} .
$$

The average values of $a_{1}, a_{2}$, and $\delta$ of all the sites, typically composed of two types of soil, i.e., D and E, are presented in Table 3. This table may serve as a quick reference for using the site coefficients of soils of categories $\mathrm{D}$ and $\mathrm{E}$, present in Imphal city.

\section{PROBABILISTIC SEISMIC HAZARD}

The present methodology of PSHA follows those proposed by Cornell (1968) and Algermissen et al. (1982) and is based on the following four steps: (i) identification of sources, (ii) assessment of earthquake recurrence and magnitude distribution, (iii) selection of attenuation model for ground motion, and (iv) calculation of seismic hazard. Details of PSHA methodology adopted here have been published by the authors elsewhere (see Pallav et al. 2012) and are not repeated here. As Imphal city lies in the Imphal East District of Manipur state, seismic hazard curves for Imphal city at rock level have been taken to be same as that of Imphal East District (see Pallav et al.
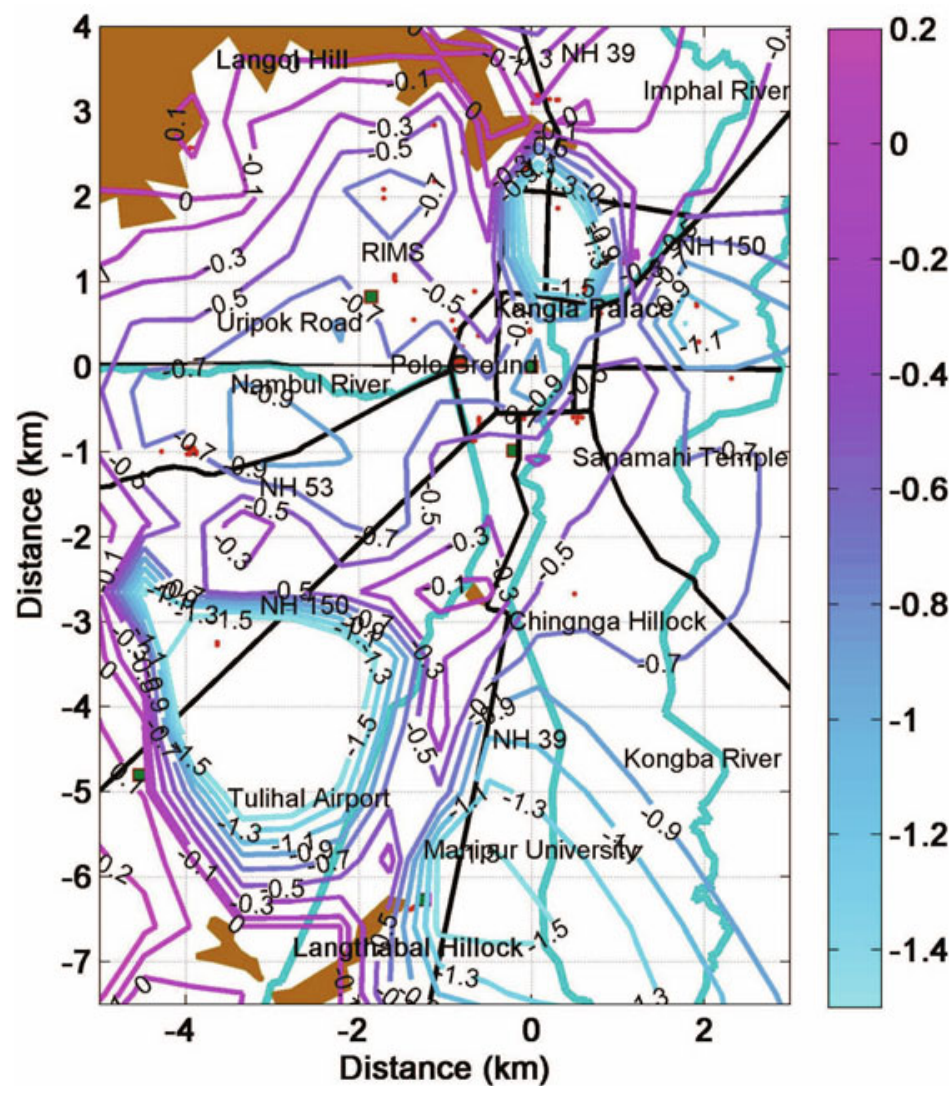

Fig. 10a. Coefficient $a_{1}$ at PGA in Imphal city $(5 \%$ damping). 
2012, for estimation of seismic hazard curves for Imphal East District) and are shown in Figs. 10a-c. It shows the seismic hazard curves for PGA at rock level obtained by means of the above-mentioned method along with the individual contributions of the seven zones. It can be seen from Fig. 11 that the hazard at Imphal is mainly controlled by IBR and SP. The contributions from other zones (EH, BB, MT, AV) are relatively low, and this may be attributed to their location at larger distances. Further on, total hazard curves are also plotted for time periods of engineering interest (e.g., 0.04, 0.1, 0.2, $0.4,1,2,3 \mathrm{~s}$; Fig. 12). Figure 13 shows UHRS for Imphal city at standard return periods of $\sim 500$ and $\sim 2500$ years, as suggested by IBC-2006. Based on the comparison with spectral acceleration $\left(S_{a}\right)$ values recommended by IS-1893 (2002) (as most of the building design are performed using this code), it can be seen that IS code overestimates the values and is on conservative side for periods from 0.2 to $0.7 \mathrm{~s}$, whilst for long period $(>1.0 \mathrm{~s})$ the IS-1893 (2002) $S_{a}$ values are on the lower side.

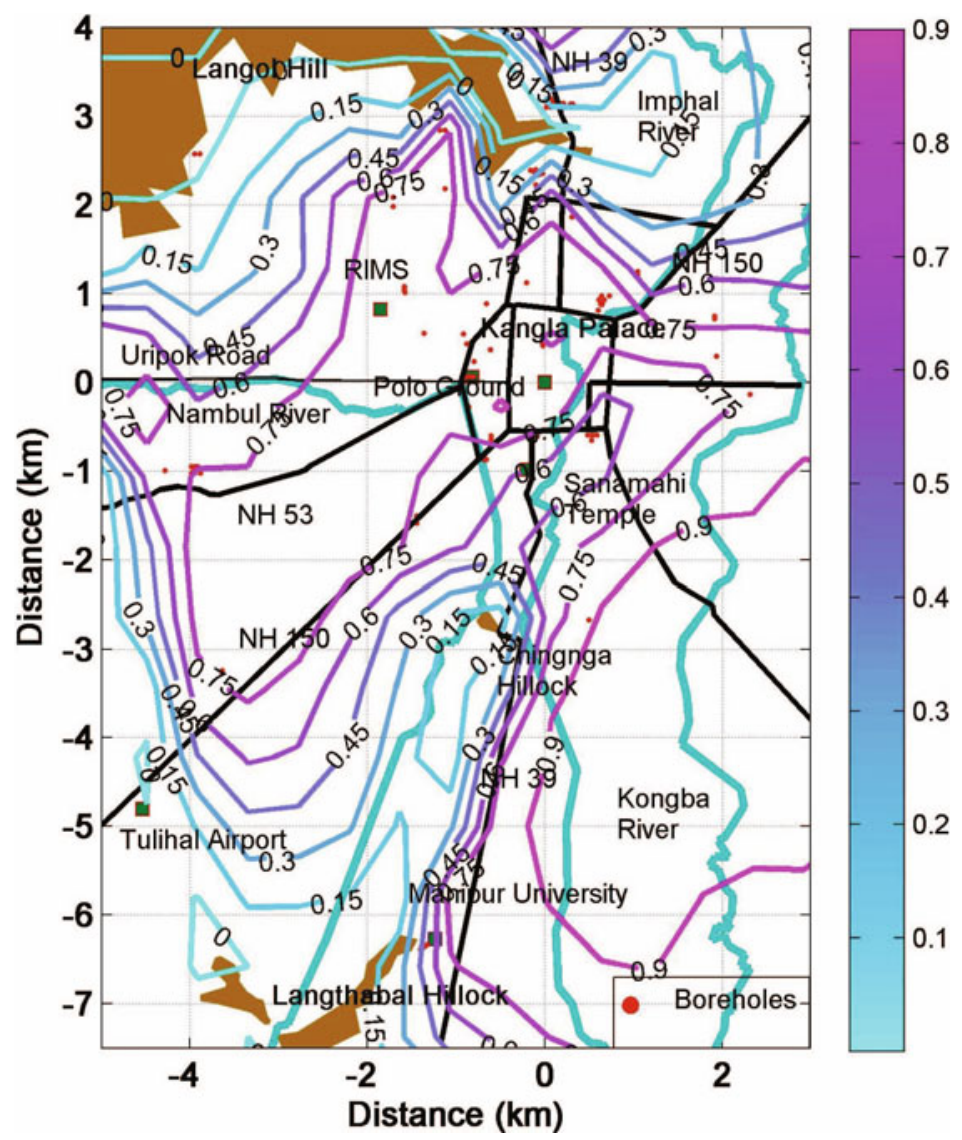

Fig. 10b. Coefficient $a_{2}$ at PGA in Imphal city $(5 \%$ damping). 

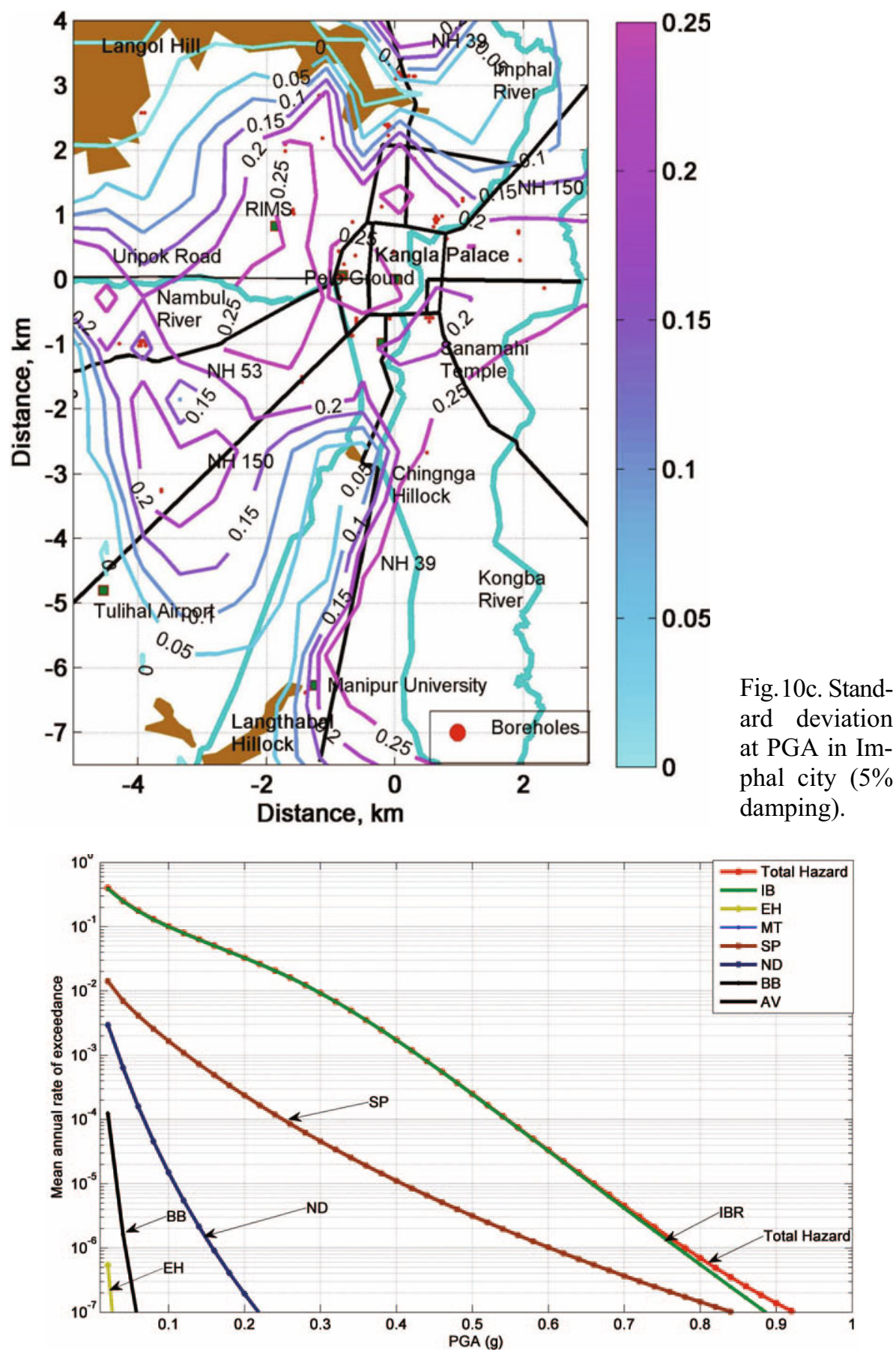

Fig. 11. Seismic hazard curves for Imphal city at rock level. 


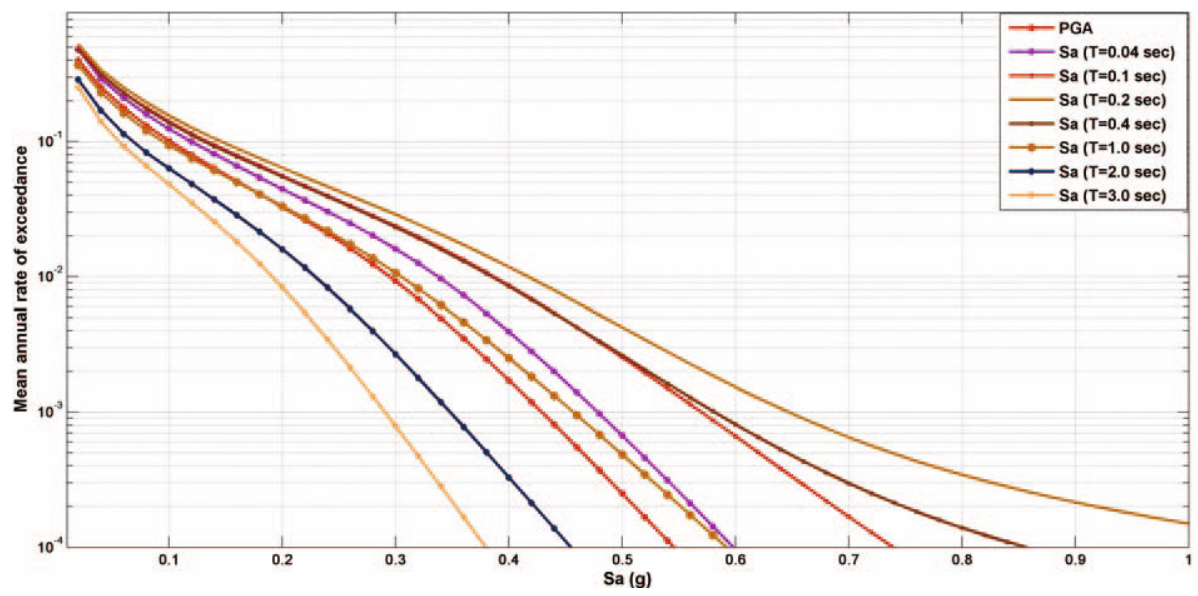

Fig. 12. Seismic hazard curves for Imphal city at rock level for all eight frequencies.

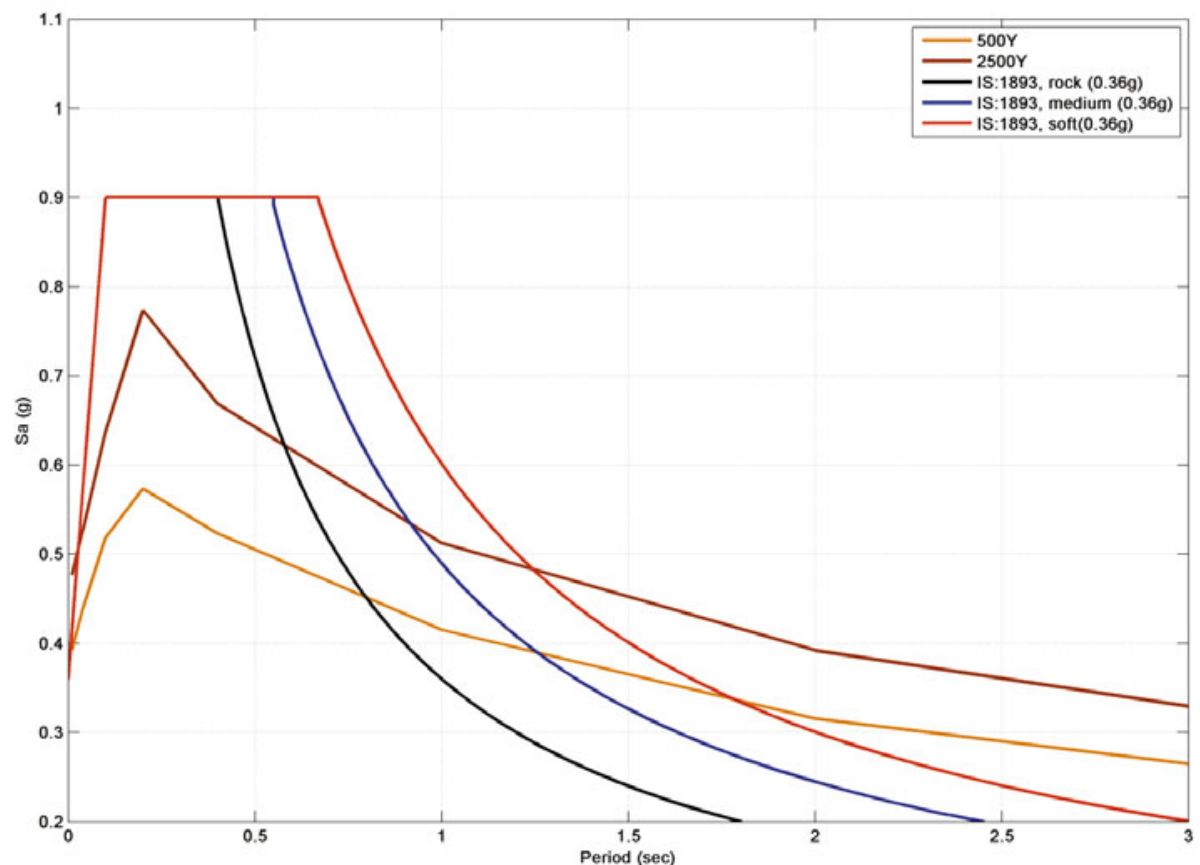

Fig. 13. Comparison of IS-1893 with Uniform Hazard Response Spectra for $\sim 500$ and $\sim 2500$ year return periods at rock level.

\section{SURFACE LEVEL HAZARD MAP FOR IMPHAL CITY}

The surface level ground motion has been estimated for $\sim 500$ and $\sim 2500$ years return period at Imphal city using $F_{s}$. Here, the UHRS computed at rock level have been multiplied by $F_{s}$ estimated at different periods for all 
122 sites in Imphal city. The results are shown in Figs. 14a-c in the form of contour plots at PGA of 0.3 and $1.0 \mathrm{~s}$ for $\sim 500$ and $\sim 2500$ year return periods with 5\% damping, as suggested by IBC-2006.

Figure 14a shows the variation of spectral acceleration at PGA for $\sim 500$ year return period at Imphal city. The maximum $S_{a}$ value attained is $0.8 \mathrm{~g}$

near the Polo Ground, whereas for short period $(0.3 \mathrm{~s})$ and long period $(1.0 \mathrm{~s})$ the $S_{a}$ maximum values observed near the Polo Ground and Kangla Palace are 1.2 and $0.9 \mathrm{~g}$, respectively (Figs. 14b-c). Further, it can been seen that at these locations $S_{a}$ exceeds the value of $0.36 \mathrm{~g} / 2$ given in IS- 1893 (2002), hence the structures designed using the IS-1893 recommended value are vulnerable.

Figure 14b shows short period spectral acceleration variation for $0.3 \mathrm{~s}$ time period with return period of $\sim 500$ years. Almost entire Imphal city is vulnerable to seismic hazard $\left(S_{a}>0.36 \mathrm{~g} / 2\right)$. In Kangla Palace, Polo Ground, RIMS and Sanamahi temple areas, spectral acceleration values reach around
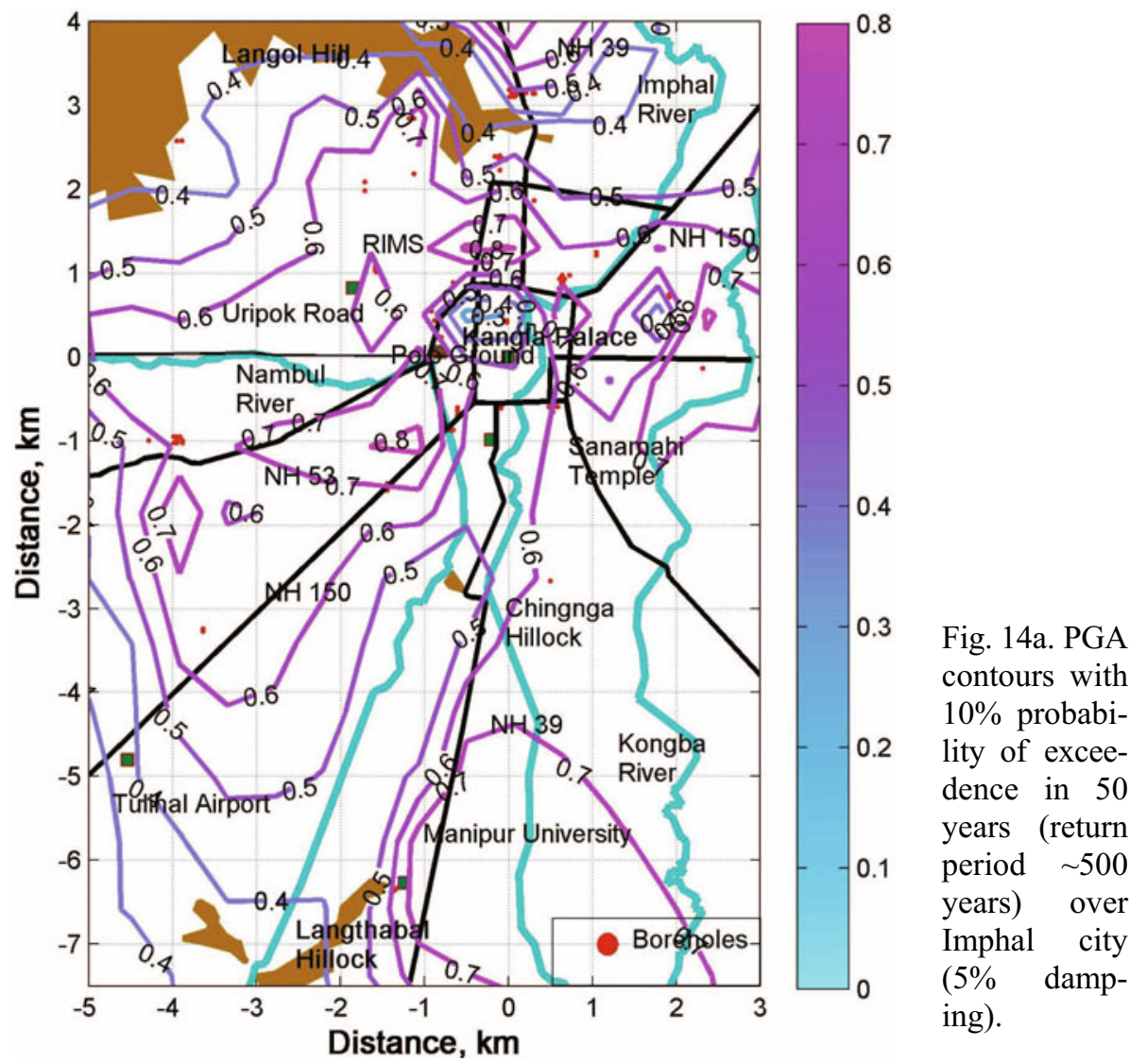


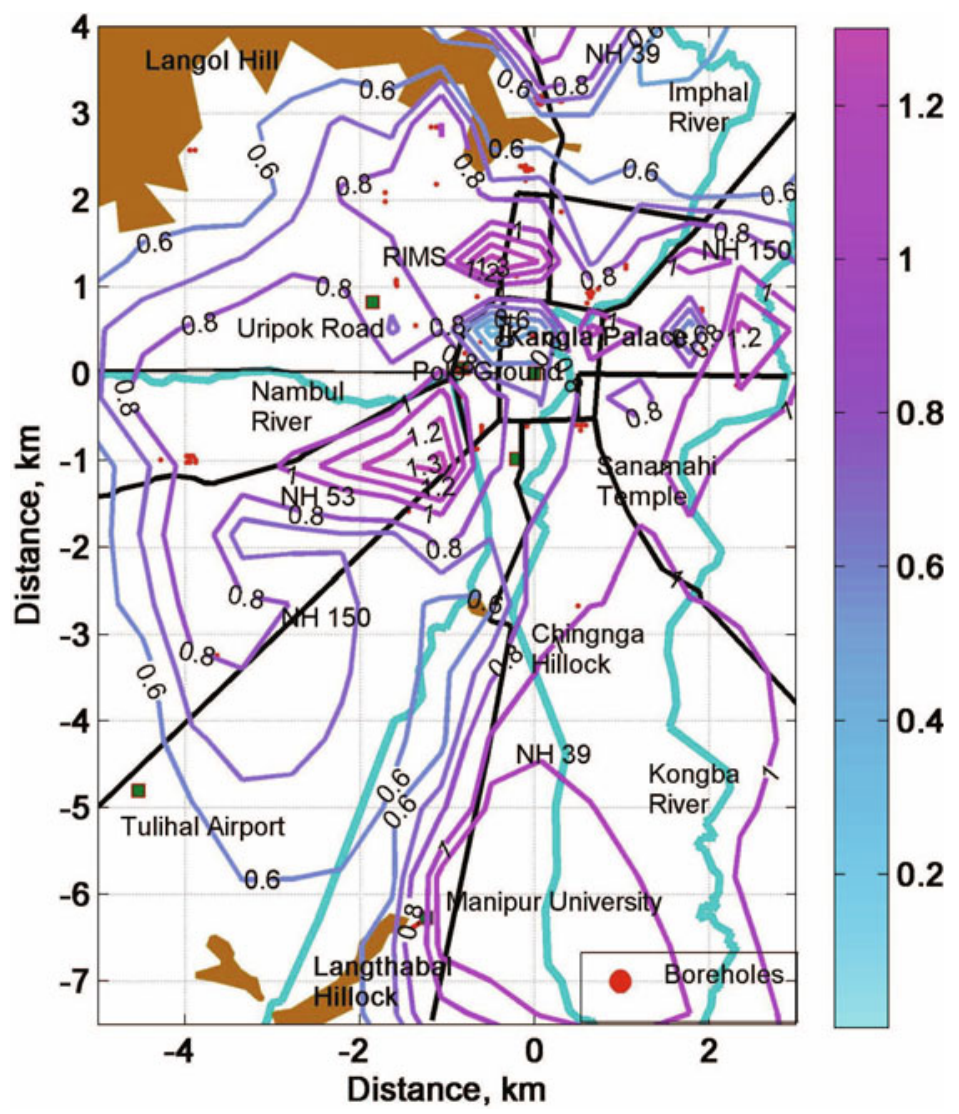

Fig. 14b. Short period spectral acceleration at $0.3 \mathrm{~s}$ with return period of $\sim 500$ years city over Imphal city (5\% damping).

0.8 to $1.2 \mathrm{~g}$. However, at the outskirts of Imphal city, i.e., near east of Langol hill, Langthabal hill, and Tulihal airport, the spectral acceleration varies between 0.6 and $0.8 \mathrm{~g}$. Variation of long period spectral acceleration for $\sim 500$ year return period at $1.0 \mathrm{~s}$ is shown in Fig. 14c. The maximum value (i.e., $1.0 \mathrm{~g}$ ) of spectral acceleration is observed near the Polo Ground and Kangla Palace area.

It may be mentioned that although in most of the codes a lesser amplification is suggested at longer periods (as compared to shorter periods), there are reports in the literature (Bazzurro and Cornell 2004, Wang et al. 2006) where soil gets amplified at long periods. The reason behind such amplification in the present case may be due soft soil deposits and presence of high water table level in the Kangla Palace area, etc.

Contours maps have also been plotted for 2500 year return periods at PGA, 0.3 and $1.0 \mathrm{~s}$ (Figs. 14a-c). From Fig. 15a, it can be observed that the maximum value of $S_{a}(0.5 \mathrm{~g})$ is observed near Kangla Palace area, whereas 

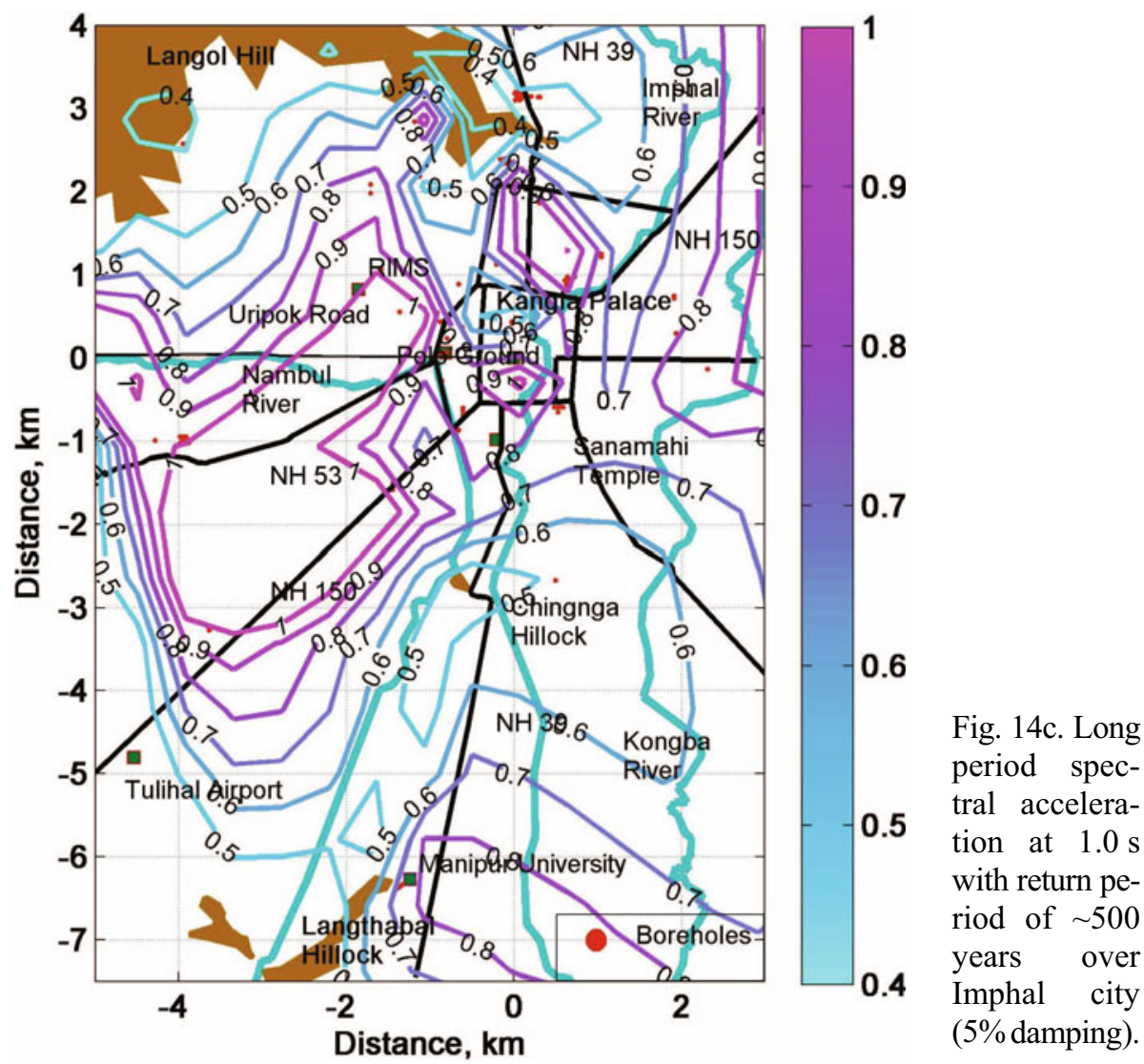

at nearby locations, i.e., Polo Ground area, there is a drastic increase in the $S_{a}$ value to $0.9 \mathrm{~g}$.

Figure $15 \mathrm{~b}$ shows short-period spectral acceleration variation at surface level at time period of $0.3 \mathrm{~s}$ in Imphal city, for 2500 year return period. It can be seen that maximum value of $S_{a}$ attained is $1.6 \mathrm{~g}$ near Polo Ground and towards north of Kangla Palace areas. Long period spectral acceleration variation for $1.0 \mathrm{~s}$ time period has been shown in Fig. 15c for 2500 year return period. Maximum $S_{a}$ value (1.2 g) has been observed at RIMS, near Nambul river and $\mathrm{NH}-150$ area (Fig. 15c).

Surface level response spectra are plotted for all 122 sites for $\sim 500$ and $\sim 2500$ year return periods in Figs. 16 and 17, respectively. It can be seen that at almost all the 122 sites the amplifications of rock level ground motion have been observed at surface levels. Comparing the present results with $S_{a}$ recommended by IS-1893 (2002) it can be found that the IS-1893 underestimates the spectra acceleration value at many locations in Imphal city, which 

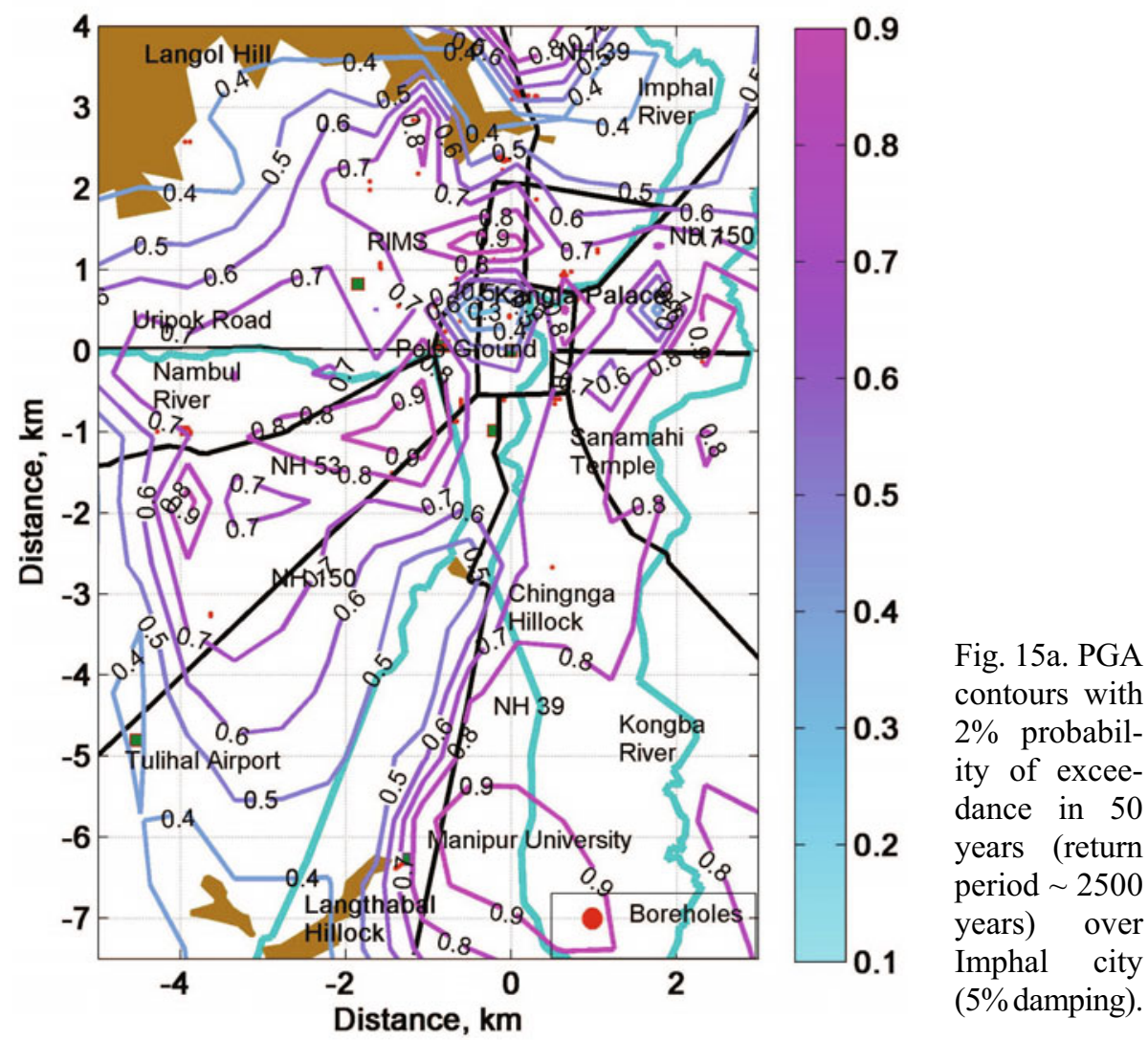

is quite a threat to this city from future hazard due to earthquake. It has been seen that the predicted mean surface level UHRS (for $\sim 500$ return period) overestimate the $S_{a}$ recommended by IS-1893 at longer period ( $>1.0 \mathrm{~s}$ ), whereas for periods greater than $0.2 \mathrm{~s}$, the IS-1893 (2002) $S_{a}$ values are underestimated for $\sim 2500$ return period.

\section{CONCLUSIONS}

Effect of near surface soil layer on seismic susceptibility of Imphal city with respect to synthetically generated 700 earthquake samples ranging in $M_{w}$ from 5.0 to 8.5 has been presented in terms of $F_{\mathrm{s}}$. Soil data collected from 122 boreholes located in Imphal city have been used as inputs in the equivalent linear site response analysis (Idriss and Sun 1992), and surface level responses were simulated for all scenario earthquakes. The shear wave velocity $\left(V_{s}\right)$ has been obtained from SPT-N values through an empirical relation proposed by Imai and Tonouchi (1982). For each site, site response 

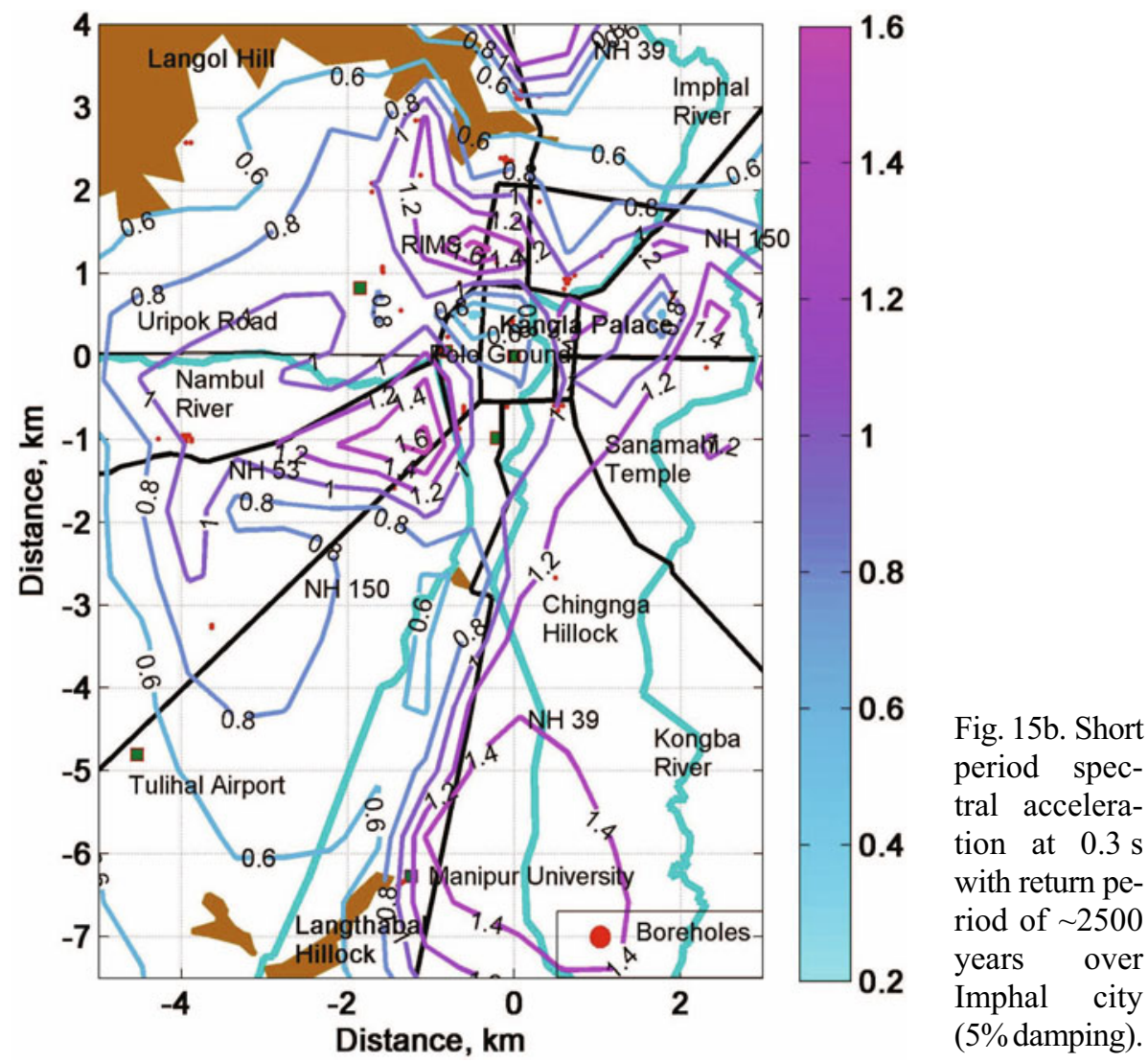

analysis (through SHAKE-91) has been performed for all 700 time-histories and correspondingly 700 site coefficients were estimated for one site for all periods of engineering interest (PGA to $3.0 \mathrm{~s}$ ) and by statistical regression, single seismic site coefficient were developed. $F_{S}$ developed in the present study have been computed at different periods of engineering purposes and these can be used for estimating surface level responses if one can know the rock level response through Eq. 3.

The present article investigates surface level ground motion using site coefficients at Imphal city using Probabilistic Seismic Hazard Analysis (PSHA). The PSHA study has been performed by incorporating site coefficients to assess the ground motion induced by potential seven seismic zones present around Imphal. Seismic hazard curves are obtained for Imphal city. Further, UHRS results are presented for 2 and $10 \%$ probability of exceedance in 50 year ( $\sim 2500$ and $\sim 500$ year) return period. It is observed that for $\sim 500$ and $\sim 2500$ year return periods, the Kangla Palace, Polo 

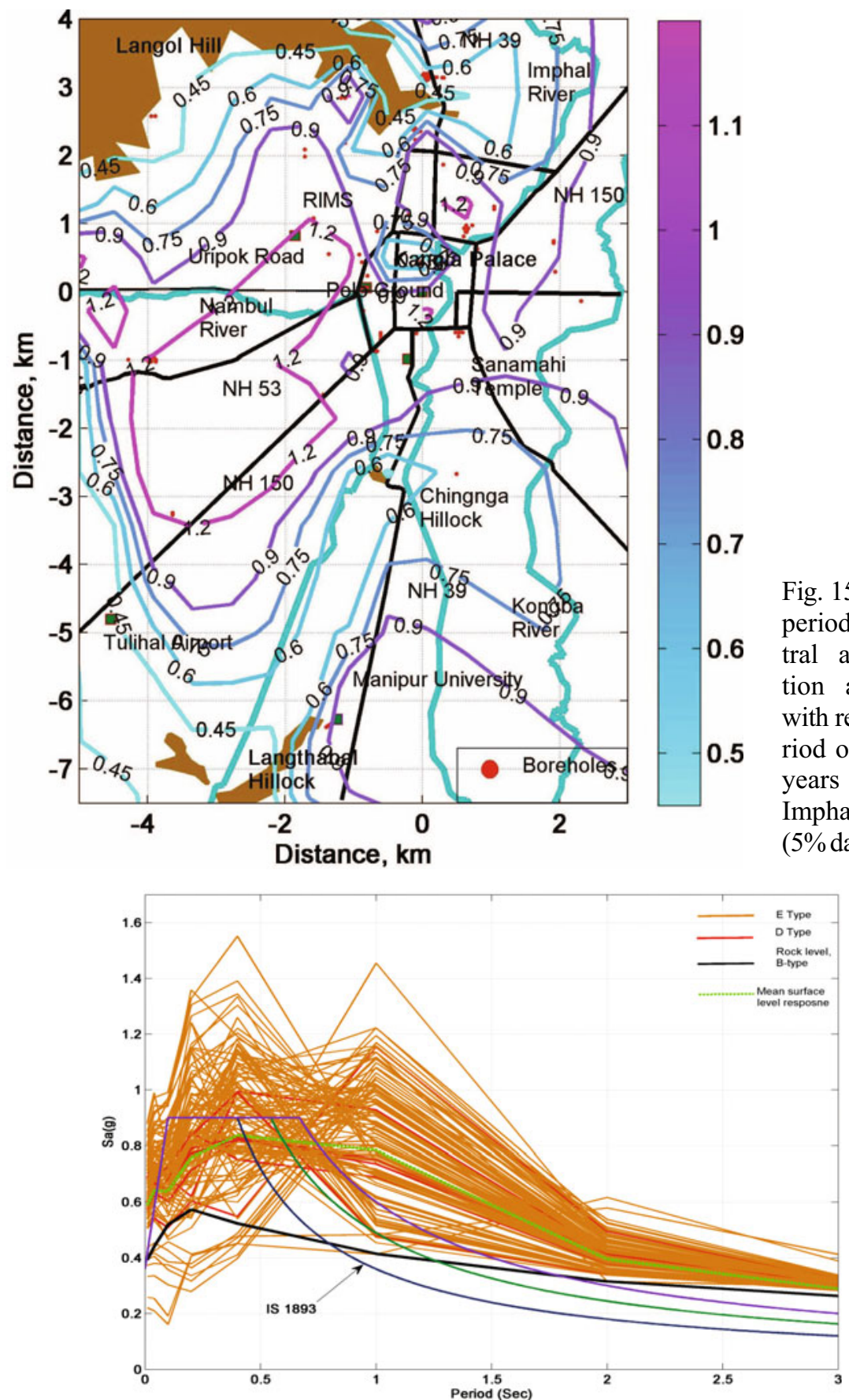

Fig. 16. Surface level response spectra for $\sim 500$ year return period for all sites in Imphal city (5\% damping). 


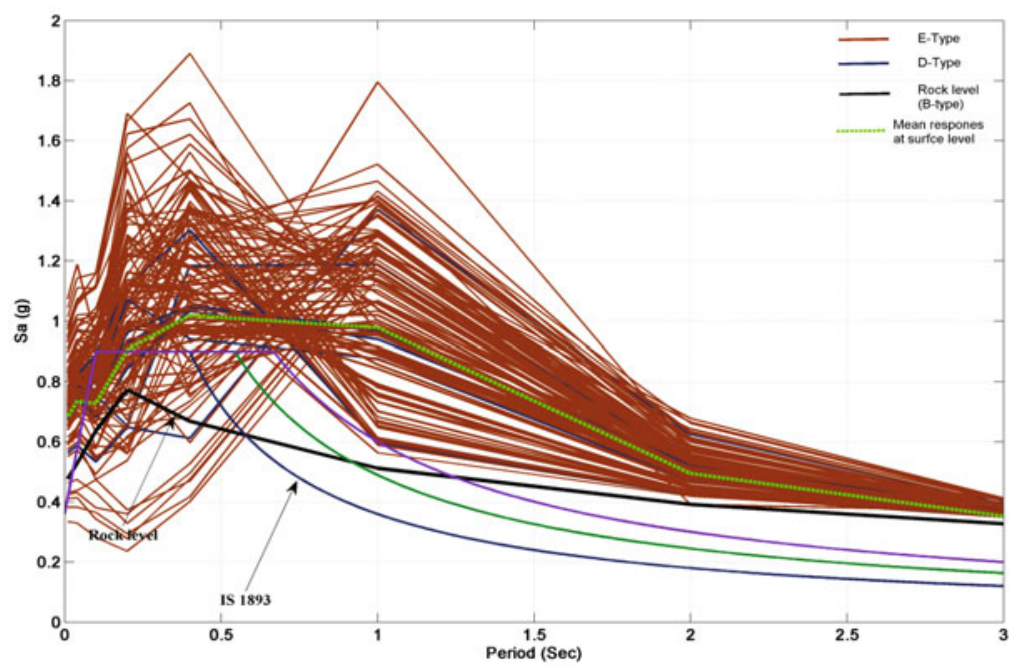

Fig. 17. Surface level response spectra for $\sim 2500$ year return period for all sites in Imphal city (5\% damping).

Ground RIMS, and near Nambul river areas of Imphal city are vulnerable. Furthermore, the predicted mean surface level response spectra were found to be higher (for longer periods, i.e., $>1.0 \mathrm{~s}$ ) for $\sim 500$ year return period, and lower for periods shorter than $0.2 \mathrm{~s}$ (for $\sim 2500$ return period) than the spectral acceleration values recommended by IS-1893 (2002).

Acknowledgement. We thank the anonymous reviewers for their valuable comments which helped us to improve the quality of the manuscript.

\section{References}

Algermissen, S.T., D.M. Perkins, P.C. Thenhaus, S.L. Hanson, and B.L. Bender (1982), Probabilistic estimates of maximum acceleration and velocity in rock in the contiguous United States, Open-file report 82-1033, United States Department of the Interior, Geological Survey, Washington, D.C., USA, 99 pp.

Anderson, J.G., and S.E. Hough (1984), A model for the shape of the Fourier amplitude spectrum of acceleration at high frequencies, Bull. Seismol. Soc. Am. 74, 5, 1969-1993.

Bazzurro, P., and C.A. Cornell (2004), Ground-motion amplification in nonlinear soil sites with uncertain properties, Bull. Seismol. Soc. Am. 94, 6, 20902109, DOI: $10.1785 / 0120030215$. 
Boore, D.M. (1983), Stochastic simulation of high-frequency ground motions based on seismological models of the radiated spectra, Bull. Seismol. Soc. Am. 73, 6A, 1865-1894.

Boore, D.M., and G.M. Atkinson (1987), Stochastic prediction of ground motion and spectral response parameters at hard-rock sites in eastern North America, Bull. Seismol. Soc. Am. 77, 2, 440-467.

Brunnschweiler, R.O. (1974), Indoburman ranges. In: A.M. Spenceer (ed.), Mesozoic-Cenozoic Orogenic Belts: Data for Orogenic Studies, Special Publ., Vol. 4, Scottish Academic Press Ltd for the Geological Society, London, 279-299.

BSSC (1995), 1994 Edition - NEHRP Recommended Provisions for Seismic Regulations for New Buildings. Part 1 - Provisions (FEMA 222A), Building Seismic Safety Council, Washington, DC.

Cornell, C.A. (1968), Engineering seismic risk analysis, Bull. Seismol. Soc. Am. 58, 5, 1583-1606.

Goswami, H.C., and S.K. Sarmah (1982), Probabilistic earthquake expectancy in the northeast Indian region, Bull. Seismol. Soc. Am. 72, 3, 999-1009.

GSI (2000), Seismotectonic Atlas of India and its Environs, Geological Survey of India, Calcutta, $86 \mathrm{pp}$.

Haokip, S.N. (2007), Basine Delineation Map of Manipur. Profile on State of Environment Report of Manipur, Ministry of Environment and Forests, Manipur, India, $4 \mathrm{pp}$.

Hwang, H.H.M., H. Lin, and J.R. Huo (1997), Site coefficients for design of buildings in eastern United States, Soil Dyn. Earthq. Eng. 16, 1, 29-40, DOI: 10.1016/S0267-7261(96)00031-0.

IBC-2006 (2006), International Building Code 2006 Edition, International Code Council.

Ibotombi, S. (2000), Structural and tectonic framework of Manipur. In: Manipur Science Congress, Manipur University, Imphal, India.

Idriss, I.M., and J.I. Sun (1992), SHAKE-91: A computer program for conducting equivalent linear seismic response analyses of horizontally layered soil deposits, Center for Geotechnical Modeling, Department of Civil and Environmental Engineering, University of California, Davis, USA.

Imai, T., and K. Tonouchi (1982), Correlation of N-value with S-wave velocity and shear modulus. In: Proc. 2nd European Symposium on Penetration Testing, May 1982, Amsterdam, The Netherlands, 57-72.

IS-1893 (2002), Criteria for earthquake resistant design of structures. Part 1 - General provisions and buildings, 5th revision, Bureau of Indian Standards, New Delhi, India.

Laiba, M.T. (1992), The Geography of Manipur, Public Book Store, Imphal.

Martin, G.R., and R. Dobry (1994), Earthquake site response and seismic code provisions, NCEER Bull. 8, 4, 121-129. 
MASTEC (2007), Final report on water harvesting and water conservation in Imphal East I Block, Imphal East District, Manipur, Manipur Science and Technology Council, Imphal, India, 90 pp., http://mastec.nic.in/mastec/ report $\% 20$ water $\% 20$ harvesting.pdf.

Motazedian, D., and G.M. Atkinson (2005), Stochastic finite-fault modeling based on a dynamic corner frequency, Bull. Seismol. Soc. Am. 95, 3, 995-1010, DOI: $10.1785 / 0120030207$.

Nandy, D.R. (2001), Geodynamics of Northeastern India and the Adjoining Region, ACB Publications, Kolkata, 209 pp.

Pallav, K., S.T.G. Raghukanth, and K.D. Singh (2010), Surface level ground motion estimation for 1869 Cachar earthquake (Mw 7.5) at Imphal city, J. Geophys. Eng. 7, 3, 321-331, DOI: 10.1088/1742-2132/7/3/010.

Pallav, K., S.T.G. Raghukanth, and K.D. Singh (2012), Probabilistic seismic hazard estimation of Manipur, India, J. Geophys. Eng. 9, 5, 516-533, DOI: 10.1088/1742-2132/9/5/516.

Park, D., and Y.M.A. Hashash (2005), Evaluation of seismic site factors in the Mississippi Embayment. II. Probablisitic seismic hazard analysis with nonlinear site effects, Soil Dyn. Earthq. Eng. 25, 2, 145-156, DOI: 10.1016/ j.soildyn.2004.10.003.

PTI (2010), Rail link from Manipur to Vietnam on cards: Tharoor, Press Trust of India, April 9, http://timesofindia.indiatimes.com/india/Rail-link-fromManipur-to-Vietnam-on-cards-Tharoor/articleshow/5778641.cms.

Raghukanth, S.T.G., and S.N. Somala (2009), Modeling of strong-motion data in northeastern India: Q, stress drop, and site amplification, Bull. Seismol. Soc. Am. 99, 2A, 705-725, DOI: 10.1785/0120080025.

Raghukanth, S.T.G., K.D. Singh, and K. Pallav (2009), Deterministic seismic scenarios of Imphal City, Pure Appl. Geophys. 166, 4, 641-672, DOI: 10.1007/ s00024-009-0460-y.

Schnabel, P.B., J. Lysmer, and H.B. Seed (1972), SHAKE - a computer program for earthquake response analysis of horizontally layered sites, Report No. EERC-72/12, University of California, Berkeley, USA.

Singh, R.K.H. (2004), Tectonic significance of minor structures of the rocks of Imphal Valley, Ph.D. Thesis, Manipur University, Imphal, India.

Vucetic, M., and R. Dobry (1991), Effect of soil plasticity on cyclic response, J. Geotech. Eng. 117, 1, 89-107, DOI: 10.1061/(ASCE)0733-9410(1991) 117:1(89).

Wang, K., Q.F. Chen, S. Sun, and A. Wang (2006), Predicting the 1975 Haicheng earthquake, Bull. Seismol. Soc. Am. 96, 3, 757-795, DOI: 10.1785/ 0120050191 . 